\title{
Selection of Suitable Reference Genes for Quantitative Real-time Polymerase Chain Reaction in Prunus mume during Flowering Stages and under Different Abiotic Stress Conditions
}

\author{
Tao Wang, Ruijie Hao, Huitang Pan, Tangren Cheng, and Qixiang Zhang ${ }^{\mathbf{1}}$ \\ Beijing Key Laboratory of Ornamental Plants Germplasm Innovation \& Molecular Breeding, \\ National Engineering Research Center for Floriculture and College of Landscape Architecture, \\ Beijing Forestry University, Beijing 100083, China
}

\begin{abstract}
AdDiTIONAL INDEX WORDS. gene expression, mei, normalization
Abstract. Mei (Prunus mume) is widely cultivated in eastern Asia owing to its favored ornamental characteristics and its tolerance for low temperatures. Reverse transcription quantitative real-time polymerase chain reaction (qRTPCR) is a widely used method for gene expression analysis, requiring carefully selected reference genes to ensure data reliability. The aim of this study was to identify and evaluate reference genes for qRT-PCR in mei. Ten candidate reference genes were chosen, and their expression levels were assessed by qRT-PCR in four sample sets: 1) flowering mei; 2) mei undergoing abiotic stress; 3) different genotypes of Prunus species; and 4) all mei samples. The stability and suitability of the candidate reference genes were validated using commercially available software. We found that protein phosphatase 2A-1 $(P P 2 A-1)$ and $P P 2 A-2$ were suitable reference genes for flowering with ubiquitinconjugating enzyme E2 $(U B C)$ also being suitable for different genotypes of Prunus species. $U B C$ and actin $(A C T)$ were most stably expressed under abiotic stress. Finally, the expression of an AGAMOUS homolog of Arabidopsis thaliana $(P m A G)$ and a putative homolog of Group 2 late embryogenesis abundant protein gene in $A$. thaliana $(P m L E A)$ were assessed to allow comparisons between selected candidate reference genes, highlighting the importance of careful reference gene selection.
\end{abstract}

Prunus mume belongs to the family Rosaceae, subfamily Prunoideae, and was cultivated in China more than 3000 years ago for its ornamental qualities and its fruit (Chen, 1996). As an early-blooming garden ornamental, mei is widely cultivated in eastern Asia owing to its favored ornamental characteristics, including colorful corollas, varying types of flowers, and pleasant fragrance. It is also favored because of its inherent tolerance to low temperatures, allowing it flowers in winter or early spring, while most other ornamental trees are still dormant (Chen, 1996; Sun et al., 2013). These unique properties give mei high cultural and commercial value in both China and elsewhere.

Previous research on mei has primarily focused on its physiological and biochemical characteristics (Chen, 2012; Li et al., 2011; Zhang, 2011; Zhao et al., 2010); however, relatively few studies have focused on the transcription and expression of genes in mei, and we have little knowledge on concerning the genetic mechanisms underlying the biological and ornamental traits of mei. Recently, the draft genome sequence of mei has been published (Zhang et al., 2012b), thus providing a strong foundation for gene profiling studies in mei and facilitating genome-level comparisons among Prunus species. We believe the availability of the mei genome will stimulate research in the functional genomics of the Prunus genus.

Received for publication 17 Sept. 2013. Accepted for publication 10 Dec. 2013. This work was supported by Ministry of Science and Technology (Grant No. 2011AA100207, 2013AA102607) and Beijing Science and Technology Project, People's Republic of China (Grant No. Z131105002813013).

${ }^{1}$ Corresponding author. E-mail: zqxbjfu@126.com.
Real-time reverse transcription polymerase chain reaction is a sensitive method that is widely used to detect and verify changes in the mRNA expression levels of genes at different developmental stages (Koo et al., 2010; Vaucheret et al., 2004) and under various abiotic stress (Borges et al., 2012; Du et al., 2013). Normalized quantification of gene expression levels using this method depends on the stable expression of endogenous reference genes (Guénin et al., 2009). To date, stably expressed reference genes have been reported for more than 62 different plant species (summarized in Supplemental Table 1). Reference genes traditionally used in other species include $A C T$, elongation factor 1-alpha $(E F 1 \alpha)$, alpha tubulin $(T U A)$, and ubiquitin $(U B Q)$. Newer reference genes include $P P 2 A$ and SAND family protein gene $(S A N D)$, which have been used in plants because of their stable expression under different experimental conditions (Chen et al., 2010; Chi et al., 2012; Goulao et al., 2012). However, the expression levels of these genes can be changed across different samples or by external factors. Moreover, a commonly used reference gene in an organism may not be appropriate in other organisms or under different conditions (Gao et al., 2012). These reference genes (ACT, EF1 $\alpha, T U A, U B Q, P P 2 A, S A N D)$ have been found to be not stably expressed in other plants such as Fagopyrum esculentum (Demidenko et al., 2011), Phyllostachys edulis (Fan et al., 2013), Platycladus orientalis (Chang et al., 2012), and Salvia miltiorrhiza (Yang et al., 2010). Furthermore, it has been shown that there are no genes that are constantly expressed throughout the different stages in the plant's lifecycle (Fan et al., 2013; Hong et al., 2008); thus, it highlights the need to identify species- and stage-specific reference genes for qRT-PCR analyses. 
In mei, translation elongation factor 2 (TEF2) has been used as a reference gene for a putative homolog gene of Group 2 late embryogenesis abundant protein gene in Arabidopsis thaliana (PmLEA) expression analyses under abscisic acid (ABA) treatment (Du et al., 2013), and $U B Q$ has been used as a reference gene for dormancy-associated MADS-box transcription factors $(P m D A M)$ gene expression analyses associated with endodormancy (Sasaki et al., 2011). However, TEF2 and $U B Q$ were found to be unsuitable reference genes in Phaseolus vulgaris and Ammopiptanthus mongolicus (Borges et al., 2012; Shi et al., 2012). There has been no systematic analysis of suitable reference genes for development stages, different abiotic stress conditions, and different genotypes of mei. Therefore, it is necessary to carry out validation studies of reference genes used for gene expression analyses in mei.

The goal of this study was to identify suitable reference genes for conducting qRT-PCR studies in mei. We assessed the expression of 10 candidate reference genes, including $A C T$, $E F 1 \alpha, P P 2 A-1, P P 2 A-2$, RNA polymerase II (RPII), SAND, $T E F 2, T U A, U B Q$, and $U B C$, which have been previously reported to be stably expressed in $A$. thaliana (Czechowski et al., 2005), Prunus persica (Tong et al., 2009), and Rosa hybrida (Klie and Debener, 2011). The variation in expression level of these candidates was assessed by qRT-PCR in four sample sets: 1) flowering mei; 2) mei undergoing abiotic stress; 3) different genotypes of Prunus species; and 4) all mei samples. To verify the usefulness of the selected reference genes, the expression pattern of PmAG (an AGAMOUS homolog gene of A. thaliana) and PmLEA19 was analyzed in different sample sets, respectively. We believe this work will facilitate future studies on gene expression in mei and among the other Prunus species.

\section{Materials and Methods}

Plant material and treatments. All the mei samples were taken from Beijing Jiufeng International Plum Blossom Garden, Beijing, China, between July 2012 and Feb. 2013. Among them, flower samples at different developmental stages were collected from 5-year-old plants of $P$. mume 'Changrui Lve', including differentiating and developing buds and fully opened flowers. The seedlings used in the abiotic stress experiments were grown in a greenhouse at 16 to $25{ }^{\circ} \mathrm{C}$ at $60 \%$ relative humidity under a 12-h light/dark cycle. For salt, osmotic, and ABA stress treatments, 6-month-old seedlings were carefully removed from the soil, their roots were washed with tap water, and they were placed in solutions containing $150 \mathrm{~mm} \mathrm{NaCl}$, $10 \%$ polyethylene glycol 6000 (PEG6000), or $150 \mathrm{~mm} \mathrm{ABA} \mathrm{for}$ $12 \mathrm{~h}$, respectively. For the cold and heat stress treatments, the seedlings were grown at 4 or $40{ }^{\circ} \mathrm{C}$ for $12 \mathrm{~h}$, respectively. Leaves were collected from all control and experimental seedlings for further analysis.

The different genotypes tested included fully flowering samples from three botanical cultivar groups of $P$. mume: True Mei Group ( $P$. mume 'Changrui Lve', 'Danfen Chuizhi', 'Wuzhu Sha', 'Chaotang Gongfen', 'Sanlun Yudie', 'Subai Taige'), Apricot Mei Group (P. mume 'Fenghou'), Blireiana Group ( $P$. mume 'Meiren'), and some other Prunus species (P. davidiana, $P$. armeniaca, $P$. cerasifera, $P$. triloba, $P$. tomentosa, $P$. yedoensis). In all cases, samples were collected and immediately frozen in liquid nitrogen and stored at $-80{ }^{\circ} \mathrm{C}$ until RNA extraction. Samples were collected from three plants to provide three biological replicates.
Total RNA ISOLATION AND CDNA SYNTHESIS. Total RNA was extracted from samples using TRIzol reagent (Invitrogen, Carlsbad, CA) following the manufacturer's instructions. Potentially contaminating genomic DNA was eliminated by treatment with RNase-free DNase I according to the manufacturer's instructions (Promega, Madison, WI). RNA concentration and purity were determined using a spectrophotometer (Nanodrop ND-1000; Thermo Fisher Scientific, Wilmington, DE). RNA samples with an absorbance ratio at OD 260/280 between 1.9 and 2.2 and OD 260/230 less than 2.0 were used for further analysis. RNA integrity was verified by $1.5 \%$ agarose gel electrophoresis. Samples with a $28 \mathrm{~S} / 18 \mathrm{~S}$ ribosomal RNA ratio between 1.5 and 2.0 and without smears on the agarose gel were used for subsequent experiments. For each sample, $2 \mu \mathrm{g}$ of total RNA was used as a template for reverse transcription using the TIANScript cDNA First Strand cDNA Synthesis Kit (Tiangen, Beijing, China) according to the manufacturer's instructions. The cDNAs were diluted 1:10 with nuclease-free water before qRT-PCR analyses.

SELECTION OF POTENTIAL REFERENCE GENES. The 10 candidate genes evaluated in this experiment were based on the mei transcriptome data (Zhang et al., 2012b) according to meeting one or more of the following criteria: 1) reference genes traditionally used in mei for transcript normalization (Du et al., 2013; Sasaki et al., 2011); 2) reference genes described in the literature for qRT-PCR normalization in P. persica (Tong et al., 2009) or R. hybrida (Klie and Debener, 2011); and 3) mei homologs of reference genes tested for transcript level normalization and quantification in A. thaliana (Czechowski et al., 2005). BLASTN with a default setting was used to search for mei coding sequences with high similarity (e-value $10^{-6}$ ) to A. thaliana genes (Demidenko et al., 2011).

DESIGN AND DETECTION OF THE SPECIFICITY OF PRIMERS. The primers for the 10 candidate reference genes and one functional gene from mei were designed using Primer Express 2.0 software (PE Applied Biosystems, Foster, CA) with the default parameters. To verify the amplification specificity of primer pairs, universal RT-PCR using the Premix Ex Taq (TaKaRa Biotechnology, Dalian, China) was performed, and only primer pairs that showed a single amplification product with the expected amplicon size verified by $2 \%$ agarose gel electrophoresis, and no product in the no template control group, were selected for further analysis (Supplemental Fig. 1). The amplification efficiency of primer pairs (E) and correlation coefficient $\left(R^{2}\right)$ estimates were derived from a standard curve generated from a serial dilution of the mixed cDNA from all tested samples as the template performed for each candidate reference gene in triplicate.

Reverse transcription Quantitative Real-time PCR. Quantitative RT-PCR reactions were carried out in 96-well blocks with a PikoReal Real-time PCR System (Thermo Fisher Scientific, Waltham, U.K.) using the SYBR Premix Ex Taq ${ }^{\mathrm{TM}}$ Kit (TaKaRa Biotechnology) according to the manufacturer's instructions. The reactions were carried out in a $20-\mu \mathrm{L}$ volume containing $2 \mu \mathrm{L}$ of diluted cDNA, $200 \mathrm{nM}$ of each primer, and $10 \mu \mathrm{L}$ of $2 \times$ PCR Master Mix (TaKaRa Biotechnology) under the following conditions: $95^{\circ} \mathrm{C}$ for $30 \mathrm{~s}$ and 40 cycles of $95^{\circ} \mathrm{C}$ for $5 \mathrm{~s}$ and $60^{\circ} \mathrm{C}$ for $30 \mathrm{~s}$. Then, a thermal denaturing cycle of 60 to $95{ }^{\circ} \mathrm{C}$ with $0.5^{\circ} \mathrm{C}$ increment for $1 \mathrm{~s}$ was applied to determine the dissociation curves. All qRT-PCR reactions were carried out in biological and technical triplicates. A non-template control was also included in each run for each gene. The final 


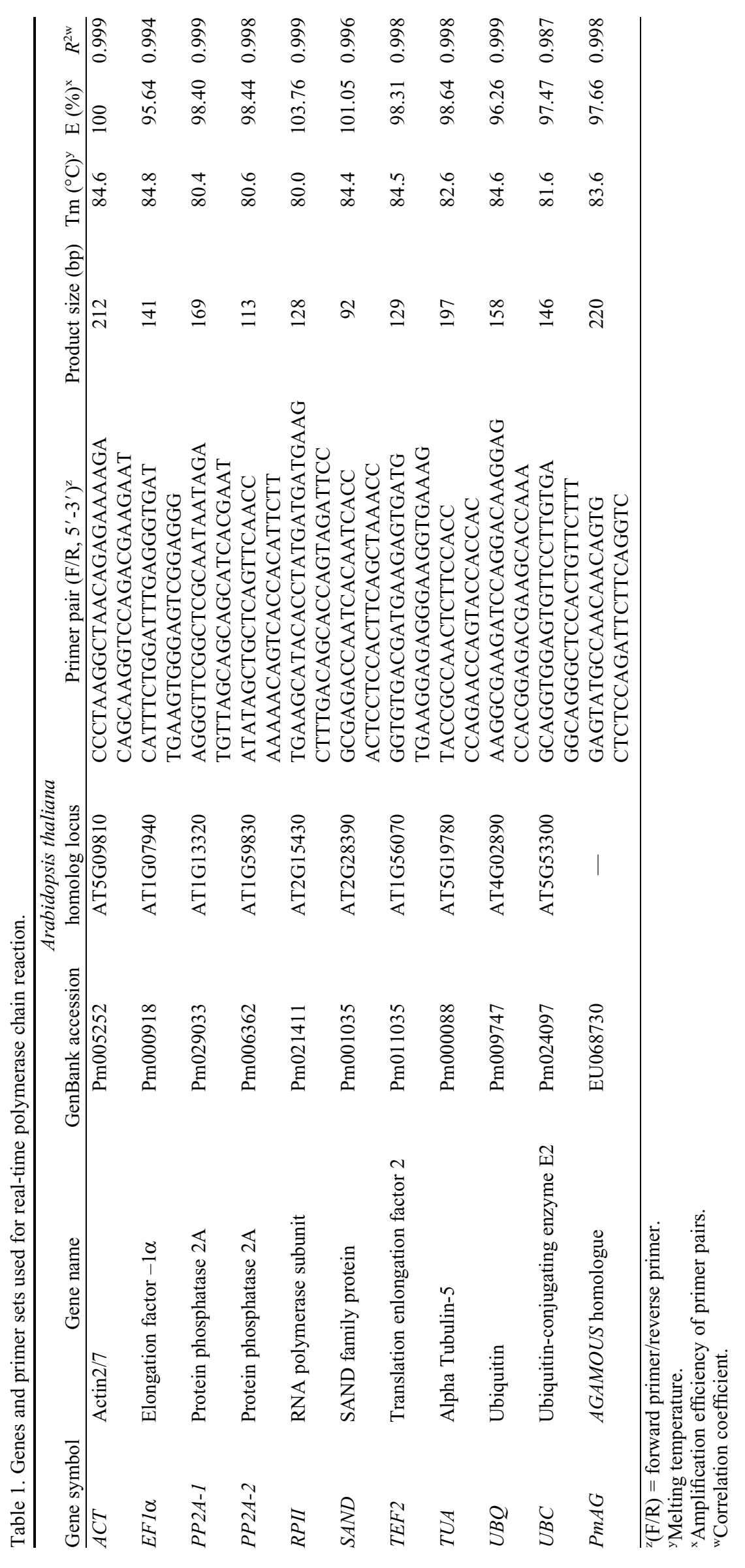


quantification cycle $(\mathrm{Cq})$ values were the means of nine values (biological triplicate, each in technical triplicate).

Statistical analyses. To select suitable reference genes, the stability of mRNA expression of each candidate gene was statistically analyzed with three publicly available Excel (Microsoft, Redmond, WA)-based software packages: geNorm (Vandesompele et al., 2002), NormFinder (Andersen et al., 2004), and BestKeeper (Pfaffl et al., 2004). All three software packages were used according to the manufacturer's instructions.

\section{Results}

Reference Gene AMPlicons, PRIMER SPECIFICITy, AND PCR AMPLIFICATION EFFICIENCY. Specific amplification for each tested primer pair was confirmed by the presence of a single peak in melting curve analysis proceeding 40 cycles of amplification (Supplemental Fig. 2). Furthermore, each amplicon was cloned and sequenced to confirm that it matches the predicted target sequence. The qRT-PCR amplification efficiency for the 10 reference genes varied from $95.64 \%$ for $E F 1 \alpha$ to $103.76 \%$ for $R P I I$; correlation coefficients ranged between 0.994 (EF1 $\alpha$ ) and 0.999 (ACT, PP2A-1, RPII, and UBQ; Table 1).

EXPRESSION PROFILING OF CANDIDATE REFERENCE GENES. A real-time qRT-PCR assay was designed for transcript profiling of the 10 candidate reference genes in 30 diverse samples (Table 1). The expression levels of the candidate reference genes were determined according to their $\mathrm{Cq}$ value with the transcripts of these genes showing different levels of abundance (Fig. 1). The average $\mathrm{Cq}$ values mostly ranged from 17 to 24 cycles across all tested samples (Fig. 1). $A C T$ and $U B C$ had the lowest $\mathrm{Cq}$ (mean $\mathrm{Cq}$ of 18.58 and 19.10, respectively), indicating the highest level of expression. TEF2 and $S A N D$ were expressed at relatively low levels (mean Cq of 23.15 and 24.71, respectively). $P P 2 A-1$ and $P P 2 A-2$ showed the least gene expression variation ( $\mathrm{CV}$ of $4.60 \%$ and $4.62 \%$, respectively), whereas TEF2 and RPII were the most variable across all samples with a CV of $10.58 \%$ and $8.99 \%$, respectively. Taken together, these results indicate that the expression level of none of the selected genes had a constant expression level and varied widely under different experimental conditions.

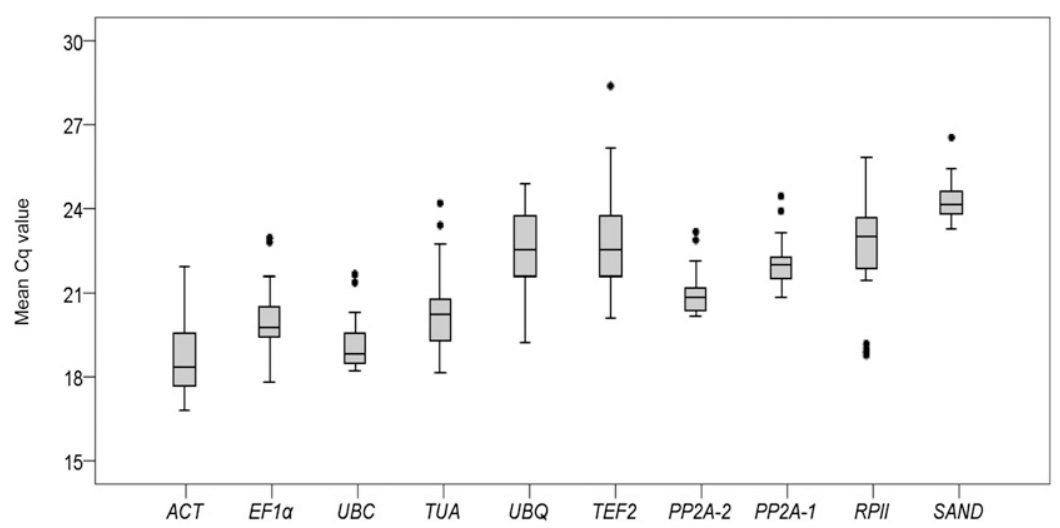

Fig. 1. Expression level of candidate reference genes across all samples. A box and whisker plot is shown for the expression level of our candidate references genes. The line across each box depicts the median, the box depicts the interquartile range, the whiskers represent the $95 \%$ confidence intervals, and the black dots represent outliers; $\mathrm{Cq}=$ final quantification cycle values.
EXPRESSION STABILITY OF CANDIDATE REFERENCE GENES. TO find the most stably expressed candidate reference gene for use with qRT-PCR in the different mei sample sets, three widely used programs were used to evaluate candidate reference gene expression: geNorm, NormFinder, and BestKeeper. Cq data were collected from all samples and were used directly for stability calculations for BestKeeper analysis and were transformed to relative quantities for geNorm and NormFinder analysis (Andersen et al., 2004; Guénin et al., 2009; Vandesompele et al., 2002).

The geNorm program is a Visual Basic application tool for Excel and was used to assess the suitability of reference genes by calculating the gene expression stability value $M$ (default value of $M \leq 1.5$ ). This program relies on the principle that the expression ratio of two reference genes should be constant throughout different experimental conditions. The most stable reference gene has the lowest $M$ value, whereas the least stable gene presents the highest $\mathrm{M}$ value (Vandesompele et al., 2002).

We analyzed four gene expression sample sets from mei using geNorm (Fig. 2). For the flowering developmental stages and different genotype samples, $P P 2 A-2$ and $U B C$ were the most stably expressed genes with the lowest $M$ values, ranking at the top position when all 21 mei samples were analyzed together (Figs. 2A, 2B, and 2D). Under these experimental conditions, the geNorm ranked TEF2 in the last position with the highest $\mathrm{M}$ value. When the samples under abiotic stress were analyzed, $P P 2 A-2$ and $A C T$ showed the most stable expression and ranked top, whereas EFla ranked at the bottom (Fig. 2C).

Evaluation of our expression data revealed that $U B C$ and $P P 2 A-2$ ranked at the top at flower developmental stages samples in mei and for different genotypes of Prunus species, indicating that these genes were stably expressed and may be suitable reference genes for qRT-PCR normalization; $A C T$ and $P P 2 A-2$ ranked at the top when evaluation of our expression data under abiotic stressed in mei, indicating that these genes may be suitable reference genes for qRT-PCR normalization for abiotic-stressed samples in mei. On the other hand, TEF2 and EFIa were the least suitable reference genes under our experimental conditions.

Through calculating the pairwise variation $\left(\mathrm{V}_{\mathrm{n}} / \mathrm{V}_{\mathrm{n}+1}\right)$ between $\mathrm{NF}_{\mathrm{n}}$ and $\mathrm{NF}_{\mathrm{n}+1}$, geNorm also determines the optimal number of reference genes required for effective normalization in qRT-PCR. Vandesompele et al. (2002) proposed $\mathrm{V}_{\mathrm{n}} / \mathrm{V}_{\mathrm{n}+1}$ less than 0.15 , meaning that 0.15 is the cutoff value for $\mathrm{V}$; if $\mathrm{V}_{\mathrm{n}} / \mathrm{V}_{\mathrm{n}+1}$ less than 0.15 , it is not necessary to use $\geq \mathrm{n}+1$ reference genes as internal controls (Vandesompele et al., 2002). As shown in Figure 3, for samples of abiotic stress in mei and genotypes of Prunus, $\mathrm{V}_{2} / \mathrm{V}_{3}$ less than 0.15 (with values of 0.127 and 0.122 , respectively), which meant that two stable reference genes would be sufficient for accurate normalization. During the flower development process, the $\mathrm{V}_{2} / \mathrm{V}_{3}$ value was more than 0.15 , whereas the $\mathrm{V}_{3} / \mathrm{V}_{4}$ value was 0.110 , suggesting that three reference genes, $P P 2 A-2, U B C$, and $A C T$ genes, would be necessary for accurate normalization of qRT-PCR data. Similarly, when we calculated the $V_{n} / V_{n+1}$ values among all 21 tested samples of mei, $V_{3} / V_{4}$ $(0.149)$ less than 0.15 , meaning that at least three reference genes ( $P P 2 A-2, U B C$, and $P P 2 A-1)$ would be necessary for normalization. 

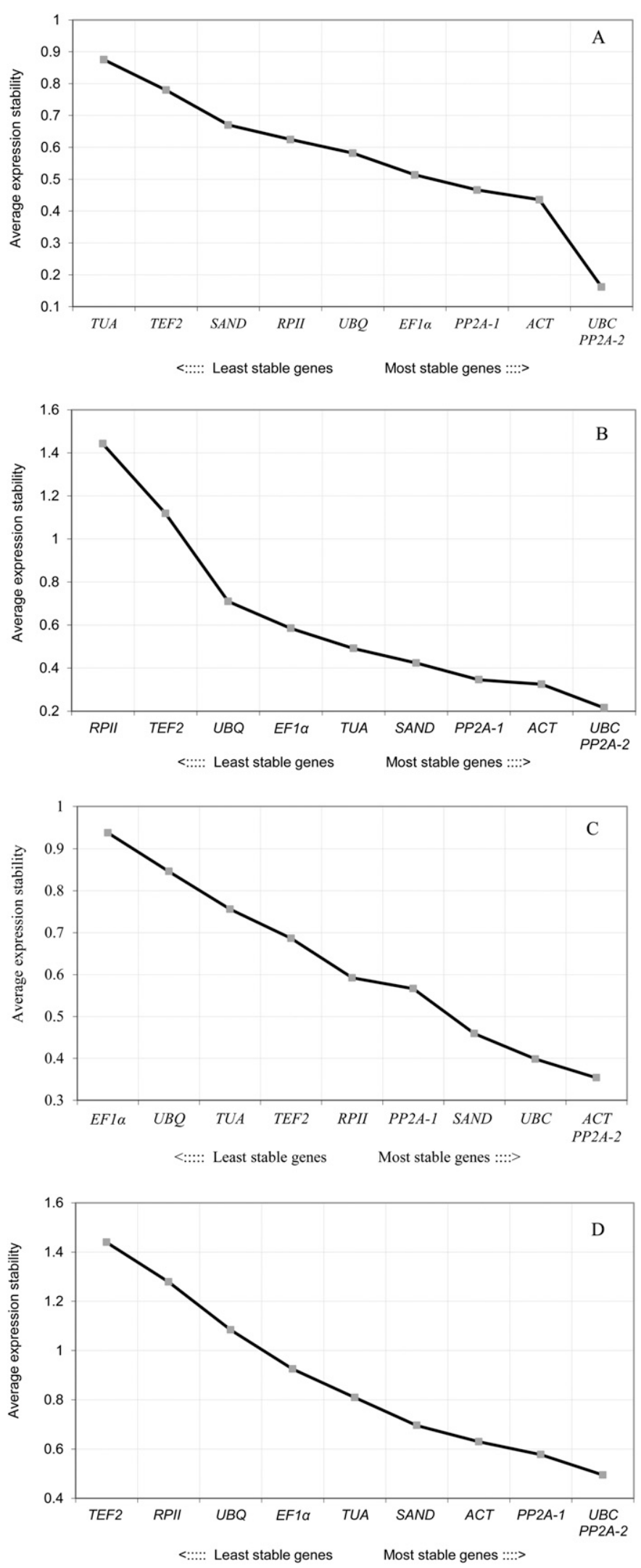

Fig. 2. Average expression stability of candidate reference genes was evaluated by geNorm program (Vandesompele et al., 2002), which calculates an average expression stability values (M) based on the average pairwise variation existing between all pairs of the candidate genes for samples at flower development stages (A), different Prunus genotypes (B), under abiotic stress (C), and all mei samples (D). A lower M value indicates more stable expression.

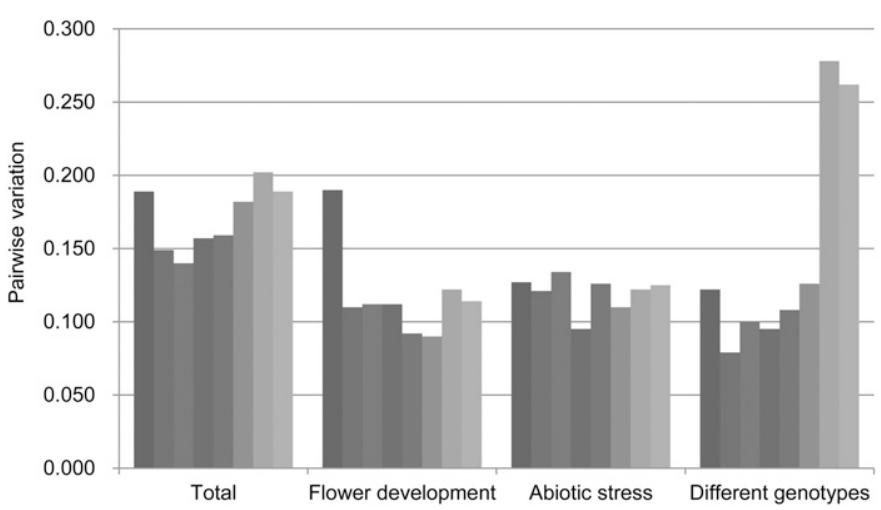

Fig. 3. Pairwise variation (V) between $\mathrm{NF}_{\mathrm{n}}$ and $\mathrm{NF}_{\mathrm{n}+1}$ measurements of the candidate reference genes by geNorm program (Vandesompele et al., 2002). When $V_{n} / V_{n+1}$ is less than 0.15 , then the optimal number of reference genes is $\mathrm{N}$.

The NormFinder program is another Excel-based application used to determine the expression stability of reference genes, which is based on a variance estimation approach that ranks all reference gene candidates based on intra- and intergroup variations and combines both results into a stability value for each candidate reference gene. In this program, stable gene expression is indicated by lower average expression stability values (Andersen et al., 2004).

As shown in Supplemental Table 2, the rankings of the top candidate reference genes determined by NormFinder were consistent with those determined by geNorm with some minor differences. For flower developmental stages samples, $A C T$ showed the lowest expression stability value when determined by NormFinder followed by $P P 2 A-1$, whereas it ranked third with geNorm. When we evaluated the different genotypes, NormFinder determined $P P 2 A-2$ and $P P 2 A-1$ to be the top two most stably expressed genes, whereas $P P 2 A-2$ ranked first and $P P 2 A-1$ ranked forth by geNorm. When we evaluated all the mei samples, $P P 2 A-1$ emerged as the most stably expressed, whereas it was ranked third by geNorm. When we considered the least stable genes, both methods showed the same results with the least stable genes being TEF2 and RPII across all samples and different genotypes, whereas TUA and TEF2 were bottom during the flower developmental process.

The BestKeeper program is another Excel-based program designed to analyze the stability of candidate reference genes based on the $\mathrm{CV}$ and the SD of the raw $\mathrm{Cq}$ values. Reference genes with the lowest $\mathrm{CV} \pm \mathrm{SD}$ values were identified as the most stable genes (Pfaffl et al., 2004). Many suitable reference genes for given experimental conditions in many plants have been successfully evaluated using this method (Chang et al., 2012; Cordoba et al., 2011; Fan et al., 2013; Zhu et al., 2013) with genes with a SD greater than 1 being considered unacceptable (Chang et al., 2012; Cordoba et al., 2011; Zhu et al., 2013).

As shown in Supplemental Table 2, during the flower developmental process, $P P 2 A-2$ ranked in the top position using BestKeeper and geNorm but ranked eighth using NormFinder. Under the abiotic stress conditions, $U B C$ had the lowest $\mathrm{CV}$ value $(0.76)$ with a SD $(0.15)$ lower than 1 , showing the most stable expression. This was in agreement with NormFinder, although it was ranked third by geNorm. Among the samples from different Prunus species, $U B C$ and $P P 2 A-2$ ranked in the top two positions using BestKeeper, which was in agreement 
with geNorm although the order was different, because $P P 2 A-2$ was ranked first and $U B C$ ranked fourth according to NormFinder. When we evaluated gene stability across all the experimental samples of mei using BestKeeper, PP2A-1 emerged as the most stably expressed gene, which was also ranked first by NormFinder and third by geNorm. When we evaluated the least stable genes, BestKeeper showed similar results as the other two methods of analysis with TUA and TEF2 ranked bottom during the flower developmental process, $E F 1 \alpha$ ranked bottom among the abiotic-stressed samples, and TEF2 and RPII ranked bottom across the different genotypes.

REFERENCE GENE VALIDATION. The AGAMOUS gene plays an important role during the development of the reproductive organs in plants (Die et al., 2010; Hou et al., 2011; Ito et al., 2004). Dehydrins play important roles in plant desiccation tolerance. The expression of PmLEA19 was up-regulated under various abiotic stress treatments $(\mathrm{Du}, 2013)$. The use of different reference genes to calculate relative expression data of genes can have a significant influence on the final normalized results (Chang et al., 2012; Fan et al., 2013; Ito et al., 2004).

When normalized using the two most stable reference genes (PP2A-1 and $P P 2 A-2)$ and several middle-ranked stable gene combinations $(U B C+A C T$ and $U B C+A C T+E F 1 a)$ calculated by three software programs (Table 2) as an internal control, the relative expression level of $P m A G$ showed a similar trend with slightly variability during bud development process. However, these were observed to be completely different when the least stable reference genes, TEF2 and TUA, were used as the internal control (Fig. 4A).

Among the samples with different genotypes, $P P 2 A-1$, $P P 2 A-2$, and $U B C$ were the top ranked references genes as determined by all three software programs. When using these genes as internal controls, $P m A G$ expression showed a similar trend. When the bottom ranked $R P I I$ gene was used for normalization, the expression profile of $P m A G$ showed obvious differences with overestimated expression in P. mume 'Chaotang Gongfen' and 'Sanlun Yudie' and under estimated expression in another five Prunus species (Fig. 4B).

Under the abiotic stress conditions, the expression profiles of PmLEA19 normalized using four different reference gene combinations (Fig. 4C) showed a similar trend. When $U B Q$ and $E F 1 \alpha$, unstably expressed genes (Table 2), were used as the reference for normalization, the expression profile of PmLEA19 changed (Fig. 4C).

\section{Discussion}

Gene expression studies can lead to a better understanding of the biological processes in many organisms. Specifically, reverse transcription followed by qPCR represents the most powerful technology for comparing the expression profiles of target genes (Grimplet et al., 2007; Ohdan et al., 2005). Recently, the mei genome has been made available, providing the foundation for gene expression profiling studies in mei and genome-level comparisons and analysis among different Prunus species. The use of reference genes as internal controls to normalize mRNA levels is a requirement of qRT-PCR (Wong and Medrano, 2005). To evaluate the best reference genes for different flower development stages, genotypes, and abiotic-stressed samples of mei, three different statistical approaches (geNorm, NormFinder, and BestKeeper) were used to identify the expression stability of 10 candidate reference genes. The results from these three different statistical approaches showed some differences, especially in the top ranked genes. Inconsistency among these methods is not unexpected given that they are based on distinct statistical algorithms (Andersen et al., 2004; Pfaffl et al., 2004; Vandesompele et al., 2002). Similar variability has also been observed when selecting reference genes in other plants under different conditions such as cold-stressed $P$. orientalis (Chang et al., 2012), developing Vernicia fordii seeds (Han et al., 2012),

Table 2. The ranking of the expression stability of 10 reference genes according to geNorm, NormFinder, and Bestkeeper software for all mei samples, at flower development stages, under abiotic stress, and different Prunus genotypes samples.

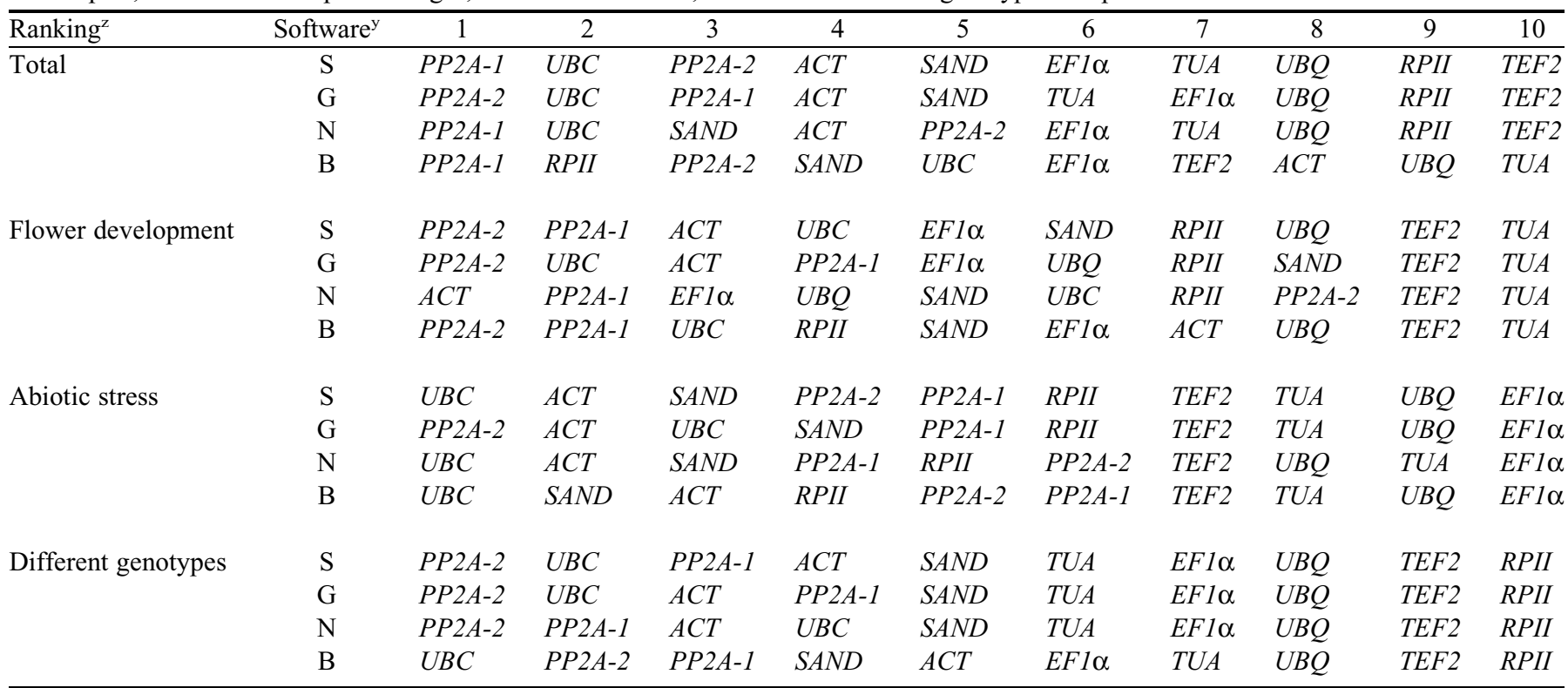

$\mathrm{z}_{1}=$ most stable gene, $10=$ least stable gene.

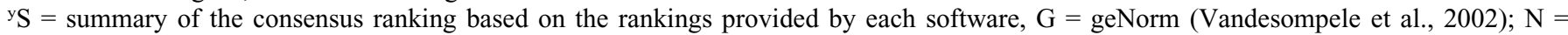
NormFinder (Andersen et al., 2004); B = Bestkeeper (Pfaffl et al., 2004). 


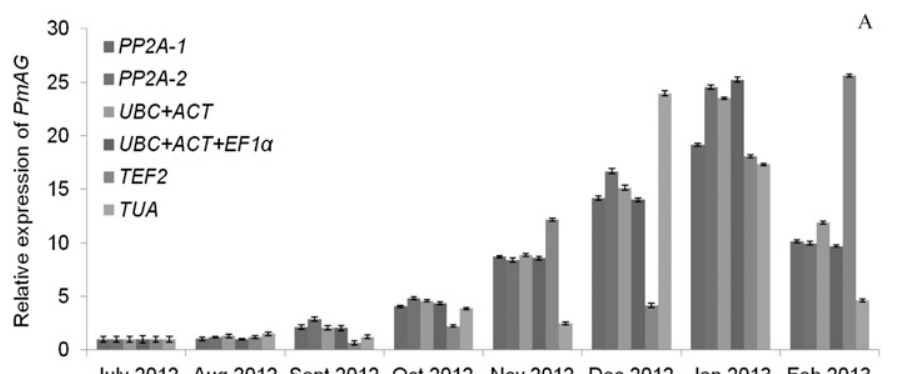

July 2012 Aug.2012 Sept.2012 Oct.2012 Nov.2012 Dec.2012 Jan.2013 Feb.2013
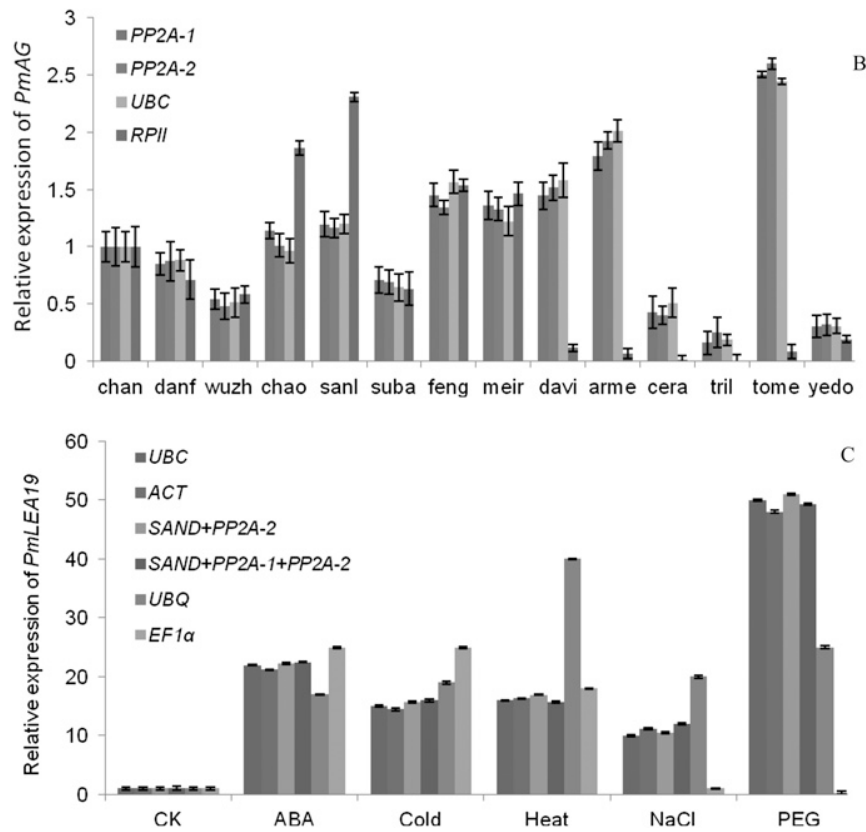

Fig. 4. Relative expression levels of an AGAMOUS homolog of Arabidopsis thaliana $(P m A G)$ and a putative homolog of Group 2 late embryogenesis abundant protein gene in A. thaliana (PmLEA19) normalized using different candidate reference genes. (A) $P m A G$ expression in mei at different flower developmental stages [different sampling times: 15 July 2012 (July 2012), 10 Aug. 2012 (Aug. 2012), 11 Sept. 2012 (Sept. 2012), 11 Oct. 2012 (Oct. 2012), 9 Nov. 2012 (Nov. 2012), 13 Dec. 2012 (Dec. 2012), 12 Jan. 2013 (Jan. 2013), 15 Feb. 2013 (Feb. 2013)] using different reference genes ( $P P 2 A-1, P P 2 A-2$, $T E F 2$, and $T U A)$ and combinations $(U B C+A C T$ and $U B C+A C T+E F 1 \alpha)$ (B) PmAG expression for different Prunus genotypes [P. mume 'Changrui Lve' (chan), P. mume 'Danfen Chuizhi' (danf), $P$. mume 'Wuzhu Sha' (wuzh), $P$. mume 'Chaotang Gongfen' (chao), $P$. mume 'Sanlun Yudie' (sanl), $P$. mume 'Subai Taige' (suba), P. mume 'Fenghou' (feng), P. mume 'Meiren' (meir), $P$. davidiana (davi), $P$. armeniaca (arme), $P$. cerasifera (cera), $P$. triloba (tril), $P$. tomentosa (tome), $P$. yedoensis (yedo)] using different reference genes (PP2A-1,PP2A-2,UBC, and RPII); (C) PmLEA19 expression in mei seedlings under different abiotic stress conditions using different reference genes $(U B C, A C T, U B Q$, and $E F 1 \alpha)$ and combinations ( $S A N D+$ $P P 2 A-2$ and $S A N D+P P 2 A-1+P P 2 A-2)$. CK $=$ seedlings without abiotic stress treatment, $\mathrm{ABA}=150 \mathrm{~mm}$ abscisic acid for $12 \mathrm{~h}, \mathrm{Cold}=4{ }^{\circ} \mathrm{C}$ for $12 \mathrm{~h}$, Heat $=40^{\circ} \mathrm{C}$ for $12 \mathrm{~h}, \mathrm{NaCl}=150 \mathrm{~mm} \mathrm{NaCl}$ for $12 \mathrm{~h}, \mathrm{PEG}=10 \%$ polyethylene glycol 6000 for 12 h. Bars indicate the SD of replicates.

different developmental stages of Carica papaya (Zhu et al., 2012), and stressed and developing Hedysarum coronarium (Cordoba et al., 2011).

In our study, the top ranked genes identified by the three different algorithms were occasionally different, but comprehensive comparison and analysis of the data showed that $P P 2 A-1$ and $P P 2 A-2$ were suitable as internal controls for gene expression normalization in sample sets of flower developmental stages and different genotypes of Prunus. The expression profiles of $P m A G$ when normalized to $P P 2 A-1$ and $P P 2 A-2$, as compared with the least stably expressed reference genes (TUA and RPII), provided superior data demonstrating that $P P 2 A-1$ and $P P 2 A-2$ were suitable reference genes for gene expression normalization. In $R$. hybrida, different tissues from three different genotypes (Klie and Debener, 2011), PP2A was ranked higher in comparison with other traditional reference genes. $P P 2 A$ has also been demonstrated to be the most stable reference gene for different genotypes and different flower and fruit developmental stages in Pisum sativum (Die et al., 2010), Gossypium hirsutum (Artico et al., 2010), Cucurbita pepo (Obrero et al., 2011), and A. thaliana (Czechowski et al., 2005).

Previously, $A C T$ has been considered to be one of the most stably expressed genes and is widely used as a reference gene for expression normalization in many plants (Fan et al., 2013; Luo et al., 2010). In the present study, $A C T$ showed the most stable expression determined by three algorithms for the abiotic-stressed samples of mei, whereas during the flowering process, $A C T$ was ranked middle by geNorm and BestKeeper, although it was still ranked top by NormFinder. The main reasons for this discrepancy may be that the $A C T$ product not only acts as a form of filament providing cells with mechanical support and driving forces for movement, but also contributes to biological processes such as sensing environmental stimuli (Fan et al., 2013; Pollard and Cooper, 2009). UBC has also been demonstrated to be stably expressed in many plants. It was identified as one of the top ranked reference genes in different floral development phases of Lycoris longituba (Cui et al., 2012); in male and female reproductive tissues, spikelets, roots, and leaves of Brachiaria brizantha (Silveira et al., 2009); and across acclimation and de-acclimation treatments of Eucalyptus globules (Fernández et al., 2010). Similarly, $U B C$ also showed the most stable expression when we evaluated abiotic-stressed samples of mei and flowering samples from different genotypes of Prunus species. When all the mei samples were analyzed together, $U B C$ was the most stably expressed reference gene we studied. In this study, $U B Q$ generally ranked fourth, sixth, or eighth when analyzed using the three algorithms, indicating that it may be unsuitable as a reference gene for gene expression normalization during the whole process of bud development, dormancy and dormancy release, and flowering, although it showed stable expression associated with endodormancy in mei (Sasaki et al., 2011), highlighting the importance of careful reference gene selection.

To our knowledge, this study is the first systematic analysis for the selection of superior reference genes for qRT-PCR in mei, for samples of flower developmental stages in mei, different genotypes of Prunus, and under different abiotic (ABA, osmotic, salt, cold, and heat) stress conditions. Analysis of expression stability using geNorm, NormFinder, and BestKeeper revealed that $P P 2 A-1$ and $P P 2 A-2$ could be considered to be appropriate reference genes for gene expression analysis for flowering mei with $U B C$ also suitable for different genotypes of Prunus species and $U B C$ and $A C T$ for samples under abiotic stress. Moreover, our results also identified the least stable reference genes, which should be avoided when analyzing gene expression levels under the given experimental conditions. This study also highlights the importance of identifying suitable reference genes for different plant species and for different experimental conditions. 


\section{Literature Cited}

Andersen, C.L., J.L. Jensen, and T.F. Ørntoft. 2004. Normalization of real-time quantitative reverse transcription-PCR data: A modelbased variance estimation approach to identify genes suited for normalization, applied to bladder and colon cancer data sets. Cancer Res. 64:5245-5250.

Artico, S., S. Nardeli, O. Brilhante, M. Grossi-de-Sa, and M. AlvesFerreira. 2010. Identification and evaluation of new reference genes in Gossypium hirsutum for accurate normalization of real-time quantitative RT-PCR data. BMC Plant Biol. 10:49.

Barsalobres-Cavallari, C.F., F.E. Severino, M.P. Maluf, and I.G. Maia. 2009. Identification of suitable internal control genes for expression studies in Coffea arabica under different experimental conditions. BMC Mol. Biol. 10:1

Bin, W.S., L.K. Wei, D.W. Ping, Z. Li, G. Wei, L.J. Bing, P.B. Gui, W.H. Jian, and C.J. Feng. 2012. Evaluation of appropriate reference genes for gene expression studies in pepper by quantitative real-time PCR. Mol. Breed. 30:1393-1400.

Borges, A., S.M. Tsai, and D.G.G. Caldas. 2012. Validation of reference genes for RT-qPCR normalization in common bean during biotic and abiotic stresses. Plant Cell Rpt. 31:827-838.

Chandna, R., R. Augustine, and N.C. Bisht. 2012. Evaluation of candidate reference genes for gene expression normalization in Brassica juncea using real time quantitative RT-PCR. PLoS One 7:e36918.

Chang, E., S. Shi, J. Liu, T. Cheng, L. Xue, X. Yang, W. Yang, Q. Lan, and Z. Jiang. 2012. Selection of reference genes for quantitative gene expression studies in Platycladus orientalis (Cupressaceae) using real-time PCR. PLoS One 7:e33278.

Chao, W.S., M. Doğramaci, M.E. Foley, D.P. Horvath, and J.V. Anderson. 2012. Selection and validation of endogenous reference genes for qRT-PCR analysis in leafy spurge (Euphorbia esula). PLoS One $7:$ e42839.

Chen, J.J. 2012. Study on the flowering process and the postharvest physiological characteristics of mei flower. Master's diss., Zhejiang A\&F Univ., Zhejiang, China.

Chen, J.Y. 1996. Chinese mei flowers. 1st Ed. Hainan Publ. House, Haikou, China [in Chinese].

Chen, K., A. Fessehaie, and R. Arora. 2012. Selection of reference genes for normalizing gene expression during seed priming and germination using qPCR in Zea mays and Spinacia oleracea. Plant Mol. Biol. Rpt. 30:478-487.

Chen, X., M. Truksa, S. Shah, and R.J. Weselake. 2010. A survey of quantitative real-time polymerase chain reaction internal reference genes for expression studies in Brassica napus. Anal. Biochem. 405:138-140.

Chi, X., R. Hu, Q. Yang, X. Zhang, L. Pan, N. Chen, M. Chen, Z. Yang, T. Wang, and Y. He. 2012. Validation of reference genes for gene expression studies in peanut by quantitative real-time RT-PCR. Mol. Genet. Genomics 287:167-176.

Cordoba, E.M., J.V. Die, C.I. Gonzalez-Verdejo, S. Nadal, and B. Román. 2011. Selection of reference genes in Hedysarum coronarium under various stresses and stages of development. Anal. Biochem. 409:236-243.

Cortleven, A., T. Remans, W.G. Brenner, and R. Valcke. 2009. Selection of plastid-and nuclear-encoded reference genes to study the effect of altered endogenous cytokinin content on photosynthesis genes in Nicotiana tabacum. Photosynth. Res. 102:21-29.

Cui, S.J., Q.L. He, Y. Chen, and M. Huang. 2012. Evaluation of suitable reference genes for gene expression studies in Lycoris longituba. J. Genet. 90:503.

Czechowski, T., M. Stitt, T. Altmann, M.K. Udvardi, and W. Scheible. 2005. Genome-wide identification and testing of superior reference genes for transcript normalization in Arabidopsis. Plant Physiol. 139:5-17.

de Oliveira, L.A., M.C. Breton, F.M. Bastolla, S. Da Silva Camargo, R. Margis, J. Frazzon, and G. Pasquali. 2012. Reference genes for the normalization of gene expression in Eucalyptus species. Plant Cell Physiol. 53:405-422.

de Vega-Bartol, J.J., R. Santos, M. Simões, and C. Miguel. 2011. Evaluation of reference genes for quantitative PCR analysis during somatic embryogenesis in conifers. BMC Proc 5:O44.

Demidenko, N.V., M.D. Logacheva, and A.A. Penin. 2011. Selection and validation of reference genes for quantitative real-time PCR in buckwheat (Fagopyrum esculentum) based on transcriptome sequence data. PLoS One 6:e19434.

Die, J.V., B. Román, S. Nadal, and C.I. González-Verdejo. 2010. Evaluation of candidate reference genes for expression studies in Pisum sativum under different experimental conditions. Planta 232:145-153.

Du, D.L. 2013. Cloning and functional analysis of dehydrins in Prunus mume. PhD diss., Beijing For. Univ., Beijing, China.

Du, D.L., Q.X. Zhang, T.R. Cheng, H.T. Pan, W.R. Yang, and L.D. Sunday. 2013. Genome-wide identification and analysis of late embryogenesis abundant (LEA) genes in Prunus mume. Mol. Biol. Rpt. 40:1937-1946.

Expósito-Rodríguez, M., A.A. Borges, A. Borges-Pérez, and J.A. Pérez. 2008. Selection of internal control genes for quantitative realtime RT-PCR studies during tomato development process. BMC Plant Biol. 8:131.

Fan, C., J. Ma, Q. Guo, X. Li, H. Wang, and M. Lu. 2013. Selection of reference genes for quantitative real-time PCR in bamboo (Phyllostachys edulis). PLoS One 8:e56573.

Fernández, M., C. Villarroel, C. Balbontín, and S. Valenzuela. 2010. Validation of reference genes for real-time qRT-PCR normalization during cold acclimation in Eucalyptus globulus. Trees (Berl.) 24:1109-1116.

Fernandez, P., J.A. Di Rienzo, S. Moschen, G.A. Dosio, L.A. Aguirrezábal, H.E. Hopp, N. Paniego, and R.A. Heinz. 2011. Comparison of predictive methods and biological validation for qPCR reference genes in sunflower leaf senescence transcript analysis. Plant Cell Rpt. 30:63-74.

Fu, J., Y. Wang, H. Huang, C. Zhang, and S. Dai. 2013. Reference gene selection for RT-qPCR analysis of Chrysanthemum lavandulifolium during its flowering stages. Mol. Breed. 31:205-215.

Gabriela, T., P.B. Adrian, C.R. Fernando, and M. Alain. 2011. Reference genes for gene expression studies in wheat flag leaves grown under different farming conditions. BMC Res. Notes 4:373.

Gamm, M., M. Héloir, J. Kelloniemi, B. Poinssot, D. Wendehenne, and M. Adrian. 2011. Identification of reference genes suitable for qRTPCR in grapevine and application for the study of the expression of genes involved in pterostilbene synthesis. Mol. Genet. Genomics 285:273-285.

Gao, Z., J. Wei, Y. Yang, Z. Zhang, and W. Zhao. 2012. Selection and validation of reference genes for studying stress-related agarwood formation of Aquilaria sinensis. Plant Cell Rpt. 31:1759-1768.

Goulao, L.F., A.S. Fortunato, and J.C. Ramalho. 2012. Selection of reference genes for normalizing quantitative real-time PCR gene expression data with multiple variables in Coffea spp. Plant Mol. Biol. Rpt. 30:741-759.

Grimplet, J., L.G. Deluc, R.L. Tillett, M.D. Wheatley, K.A. Schlauch, G.R. Cramer, and J.C. Cushman. 2007. Tissue-specific mRNA expression profiling in grape berry tissues. BMC Genomics 8:187.

Gu, C., S. Chen, Z. Liu, H. Shan, H. Luo, Z. Guan, and F. Chen. 2011. Reference gene selection for quantitative real-time PCR in Chrysanthemum subjected to biotic and abiotic stress. Mol. Biotechnol. 49:192-197.

Guénin, S., M. Mauriat, J. Pelloux, O. Van Wuytswinkel, C. Bellini, and L. Gutierrez. 2009. Normalization of qRT-PCR data: The necessity of adopting a systematic, experimental conditions-specific, validation of references. J. Expt. Bot. 60:487-493.

Han, B., Z. Yang, M.K. Samma, R. Wang, and W. Shen. 2013. Systematic validation of candidate reference genes for qRT-PCR normalization under iron deficiency in Arabidopsis. Biometals. doi: 10.1007/s10534013-9623-5. 
Han, X., M. Lu, Y. Chen, Z. Zhan, Q. Cui, and Y. Wang. 2012. Selection of reliable reference genes for gene expression studies using real-time PCR in tung tree during seed development. PLoS One 7:e43084.

Hong, S., P.J. Seo, M. Yang, F. Xiang, and C. Park. 2008. Exploring valid reference genes for gene expression studies in Brachypodium distachyon by real-time PCR. BMC Plant Biol. 8:112.

Hou, J., Z. Gao, Z. Zhang, S. Chen, T. Ando, J. Zhang, and X. Wang. 2011. Isolation and characterization of an AGAMOUS homologue PmAG from the japanese apricot (Prunus mume Sieb. et Zucc.). Plant Mol. Biol. Rpt. 29:473-480.

Huis, R., S. Hawkins, and G. Neutelings. 2010. Selection of reference genes for quantitative gene expression normalization in flax (Linum usitatissimum L.). BMC Plant Biol. 10:71.

Iskandar, H.M., R.S. Simpson, R.E. Casu, G.D. Bonnett, D.J. Maclean, and J.M. Manners. 2004. Comparison of reference genes for quantitative real-time polymerase chain reaction analysis of gene expression in sugarcane. Plant Mol. Biol. Rpt. 22:325-337.

Ito, T., F. Wellmer, H. Yu, P. Das, N. Ito, M. Alves-Ferreira, J.L. Riechmann, and E.M. Meyerowitz. 2004. The homeotic protein AGAMOUS controls microsporogenesis by regulation of SPOROCYTELESS. Nature 430:356-360.

Jiang, S., Y. Sun, and S. Wang. 2011. Selection of reference genes in peanut seed by real-time quantitative polymerase chain reaction. Intl. J. Food Sci. Technol. 46:2191-2196.

Jin, X., J. Fu, S. Dai, Y. Sun, and Y. Hong. 2013. Reference gene selection for qPCR analysis in cineraria developing flowers. Sci. Hort. 153:64-70.

Jose, C., N. Cesar, M. Giuliana, and M. Fabricio. 2011. Selection of reference genes for qPCR in hairy root cultures of peanut. BMC Res. Notes 4:392.

Klie, M. and T. Debener. 2011. Identification of superior reference genes for data normalisation of expression studies via quantitative PCR in hybrid roses (Rosa hybrida). BMC Res. Notes 4:518.

Koo, S.C., O. Bracko, M.S. Park, R. Schwab, H.J. Chun, K.M. Park, J.S. Seo, V. Grbic, S. Balasubramanian, and M. Schmid. 2010. Control of lateral organ development and flowering time by the Arabidopsis thaliana MADS-box gene AGAMOUS-LIKE6. Plant J. 62:807-816.

Lee, J.M., J.R. Roche, D.J. Donaghy, A. Thrush, and P. Sathish. 2010. Validation of reference genes for quantitative RT-PCR studies of gene expression in perennial ryegrass (Lolium perenne L.). BMC Mol. Biol. 11:8.

Li, Q., C. Fan, X. Zhang, and Y. Fu. 2012a. Validation of reference genes for real-time quantitative PCR normalization in soybean developmental and germinating seeds. Plant Cell Rpt. 31:1789-1798.

Li, X.S., H.L. Yang, D.Y. Zhang, Y.M. Zhang, and A.J. Wood. 2012b. Reference gene selection in the desert plant Eremosparton songoricum. Intl. J. Mol. Sci. 13:6944-6963.

Li, Q., S.S. Sun, D. Yuan, H. Yu, M. Gu, and Q. Liu. 2010. Validation of candidate reference genes for the accurate normalization of realtime quantitative RT-PCR data in rice during seed development. Plant Mol. Biol. Rpt. 28:49-57.

Li, R., W. Li, Y. Li, Q. Zhang, and Y. Lv. 2011. Studies on new cultivars of hardy mei flower (Prunus mume) both for flower and fruit. China Acad. J. Electronic Publ. House 2011:171-175.

Liu, Z., X. Ge, X. Wu, S. Kou, L. Chai, and W. Guo. 2013. Selection and validation of suitable reference genes for mRNA qRT-PCR analysis using somatic embryogenic cultures, floral and vegetative tissues in citrus. Plant Cell Tissue Organ Cult. 113:469-481.

Luo, H., S. Chen, H. Wan, F. Chen, C. Gu, and Z. Liu. 2010. Candidate reference genes for gene expression studies in water lily. Anal. Biochem. 404:100-102.

Mafra, V., K.S. Kubo, M. Alves-Ferreira, M. Ribeiro-Alves, R.M. Stuart, L.P. Boava, C.M. Rodrigues, and M.A. Machado. 2012. Reference genes for accurate transcript normalization in citrus genotypes under different experimental conditions. PLoS One 7:e31263.
Manoli, A., A. Sturaro, S. Trevisan, S. Quaggiotti, and A. Nonis. 2012. Evaluation of candidate reference genes for qPCR in maize. J. Plant Physiol. 169:807-815.

Maroufi, A., E. Van Bockstaele, and M. De Loose. 2010. Validation of reference genes for gene expression analysis in chicory (Cichorium intybus) using quantitative real-time PCR. BMC Mol. Biol. 11:15.

Marum, L., A. Miguel, C.P. Ricardo, and C. Miguel. 2012. Reference gene selection for quantitative real-time PCR normalization in Quercus suber. PLoS One 7:e35113.

Mehdi Khanlou, K. and E. Van Bockstaele. 2012. A critique of widely used normalization software tools and an alternative method to identify reliable reference genes in red clover (Trifolium pratense L.). Planta 236:1-13.

Migocka, M. and A. Papierniak. 2011. Identification of suitable reference genes for studying gene expression in cucumber plants subjected to abiotic stress and growth regulators. Mol. Breed. 28:343-357.

Nicot, N., J. Hausman, L. Hoffmann, and D. Evers. 2005. Housekeeping gene selection for real-time RT-PCR normalization in potato during biotic and abiotic stress. J. Expt. Bot. 56:2907-2914.

Obrero, A., J.V. Die, B. Romain, P. Goìmez, S. Nadal, and C.I. Gonzailez-Verdejo. 2011. Selection of reference genes for gene expression studies in zucchini (Cucurbita pepo) using qPCR. J. Agr. Food Chem. 59:5402-5411.

Ohdan, T., P.B. Francisco, T. Sawada, T. Hirose, T. Terao, H. Satoh, and Y. Nakamura. 2005. Expression profiling of genes involved in starch synthesis in sink and source organs of rice. J. Expt. Bot. 56:3229-3244.

Park, S., Y. Kim, C.Y. Ji, S. Park, J. Cheol Jeong, H. Lee, and S. Kwak. 2012. Stable internal reference genes for the normalization of realtime PCR in different sweetpotato cultivars subjected to abiotic stress conditions. PLoS One 7:e51502.

Patricia, G., M. Andressa, A. Ana, L. Soraya, B. David, and B. Ana. 2011. Reference genes for quantitative reverse transcription-polymerase chain reaction expression studies in wild and cultivated peanut. BMC Res. Notes 4:39.

Petit, C., F. Pernin, J. Heydel, and C. Délye. 2012. Validation of a set of reference genes to study response to herbicide stress in grasses. BMC Res. Notes 5:18.

Pettengill, E.A., C. Parmentier-Line, and G.D. Coleman. 2012. Evaluation of qPCR reference genes in two genotypes of Populus for use in photoperiod and low-temperature studies. BMC Res. Notes 5:366.

Pfaffl, M.W., A. Tichopad, C. Prgomet, and T.P. Neuvians. 2004. Determination of stable housekeeping genes, differentially regulated target genes and sample integrity: BestKeeper-Excel-based tool using pair-wise correlations. Biotechnol. Lett. 26:509-515.

Podevin, N., A. Krauss, I. Henry, R. Swennen, and S. Remy. 2012. Selection and validation of reference genes for quantitative RT-PCR expression studies of the non-model crop Musa. Mol. Breed. 30:1237-1252.

Pollard, T.D. and J.A. Cooper. 2009. Actin, a central player in cell shape and movement. Science 326:1208-1212.

Reid, K.E., N. Olsson, J. Schlosser, F. Peng, and S.T. Lund. 2006. An optimized grapevine RNA isolation procedure and statistical determination of reference genes for real-time RT-PCR during berry development. BMC Plant Biol. 6:27.

Rivera-Vega, L., P. Mamidala, J.L. Koch, M.E. Mason, and O. Mittapalli. 2012. Evaluation of reference genes for expression studies in ash (Fraxinus spp.). Plant Mol. Biol. Rpt. 30:242-245.

Saha, G.C. and G.J. Vandemark. 2013. Stability of expression of reference genes among different lentil (Lens culinaris) genotypes subjected to cold stress, white mold disease, and Aphanomyces root rot. Plant Mol. Biol. Rpt. doi: 10.1007/s11105-013-0579-y.

Sasaki, R., H. Yamane, T. Ooka, H. Jotatsu, Y. Kitamura, T. Akagi, and R. Tao. 2011. Functional and expressional analyses of PmDAM genes associated with endodormancy in japanese apricot. Plant Physiol. 157:485-497. 
Schmidt, G.W. and S.K. Delaney. 2010. Stable internal reference genes for normalization of real-time RT-PCR in tobacco (Nicotiana tabacum) during development and abiotic stress. Mol. Genet. Genomics 283:233-241.

Shi, J., M. Liu, J. Shi, G. Zheng, Y. Wang, J. Wang, Y. Chen, C. Lu, and W. Yin. 2012. Reference gene selection for qPCR in Ammopiptanthus mongolicus under abiotic stresses and expression analysis of seven ROS-scavenging enzyme genes. Plant Cell Rpt. 31:1245-1254.

Silveira, É., M. Alves-Ferreira, L. Guimarães, F. Da Silva, and V. Carneiro. 2009. Selection of reference genes for quantitative realtime PCR expression studies in the apomictic and sexual grass Brachiaria brizantha. BMC Plant Biol. 9:84.

Stolf-Moreira, R., E.G.D.M. Lemos, R.V. Abdelnoor, M.A. Beneventi, A.A.P. Rolla, S.D.S. Pereira, M.C.N.D. Oliveira, A.L. Nepomuceno, and F.C. Marcelino-Guimarães. 2011. Identification of reference genes for expression analysis by real-time quantitative PCR in drought-stressed soybean. Pesquisa Agropecu. Bras. 46:58-65.

Sun, L., W. Yang, Q. Zhang, T. Cheng, H. Pan, Z. Xu, J. Zhang, and C. Chen. 2013. Genome-wide characterization and linkage mapping of simple sequence repeats in mei (Prunus mume Sieb. et Zucc.). PLoS One 8:e59562.

Tong, Z., Z. Gao, F. Wang, J. Zhou, and Z. Zhang. 2009. Selection of reliable reference genes for gene expression studies in peach using real-time PCR. BMC Mol. Biol. 10:71.

Vandesompele, J., K. De Preter, F. Pattyn, B. Poppe, N. Van Roy, A. De Paepe, and F. Speleman. 2002. Accurate normalization of realtime quantitative RT-PCR data by geometric averaging of multiple internal control genes. Genome Biol. 3:h34.

Vaucheret, H., F. Vazquez, P. Crété, and D.P. Bartel. 2004. The action of ARGONAUTE1 in the miRNA pathway and its regulation by the miRNA pathway are crucial for plant development. Genes Dev. 18:1187-1197.

Wan, H., W. Yuan, M. Ruan, Q. Ye, R. Wang, Z. Li, G. Zhou, Z. Yao, J. Zhao, and S. Liu. 2011. Identification of reference genes for reverse transcription quantitative real-time PCR normalization in pepper (Capsicum annuum L.). Biochem. Biophys. Res. Commun. 416:24-30.

Wei, L., H. Miao, R. Zhao, X. Han, T. Zhang, and H. Zhang. 2013. Identification and testing of reference genes for sesame gene expression analysis by quantitative real-time PCR. Planta 237:873889.

Wong, M.L. and J.F. Medrano. 2005. Real-time PCR for mRNA quantitation. Biotechnology 39:1-11.

Xiao, D., N. Zhang, J. Zhao, G. Bonnema, and X. Hou. 2012. Validation of reference genes for real-time quantitative PCR normalisation in non-heading Chinese cabbage. Funct. Plant Biol. 39:342-350.
Xu, M., B. Zhang, X. Su, S. Zhang, and M. Huang. 2011. Reference gene selection for quantitative real-time polymerase chain reaction in Populus. Anal. Biochem. 408:337-339.

Xu, Y., X. Zhu, Y. Gong, L. Xu, Y. Wang, and L. Liu. 2012. Evaluation of reference genes for gene expression studies in radish (Raphanus sativus L.) using quantitative real-time PCR. Biochem. Biophys. Res. Commun. 424:398-403.

Yan, J., F. Yuan, G. Long, L. Qin, and Z. Deng. 2012. Selection of reference genes for quantitative real-time RT-PCR analysis in citrus. Mol. Biol. Rpt. 39:1831-1838.

Yang, Y., S. Hou, G. Cui, S. Chen, J. Wei, and L. Huang. 2010. Characterization of reference genes for quantitative real-time PCR analysis in various tissues of Salvia miltiorrhiza. Mol. Biol. Rep. 37:507-513.

Yi, S., Y. Qian, L. Han, Z. Sun, C. Fan, J. Liu, and G. Ju. 2012. Selection of reliable reference genes for gene expression studies in Rhododendron micranthum Turcz. Sci. Hort. 138:128-133.

Zhang, G., M. Zhao, C. Song, A. Luo, J. Bai, and S. Guo. 2012a. Characterization of reference genes for quantitative real-time PCR analysis in various tissues of Anoectochilus roxburghii. Mol. Biol. Rpt. 39:5905-5912.

Zhang, Q.X., W.B. Chen, L.D. Sun, F.Y. Zhao, B.Q. Huang, W.R. Yang, Y. Tao, J. Wang, Z.Q. Yuan, G.Y. Fan, Z. Xing, C.L. Han, H.T. Pan, Z.X. Zhong, W.F. Shi, X.M. Liang, D.L. Du, F.M. Sun, Z.D. Xu, R.J. Hao, T. Lv, Y.M. Lv, Z.Q. Zheng, M. Sun, L. Luo, M. Cai, Y.K. Gao, J.Y. Wang, Y. Yin, X. Xu, T.R. Cheng, and J. Wang. 2012b. The genome of Prunus mume. Nature Commun. 3:1318.

Zhang, W.J. 2011. Study on the physiological characteristics of 5 cultivars of Prunus mume such as 'Dongfang Zhusha' and Prunus mume in landscape. Master's diss., Zhejiang A\&F Univ., Zhejiang, China.

Zhao, Y.Q., H.T. Pan, Q.X. Zhang, C.B. Pan, and M. Cai. 2010. Dynamics of fragrant compounds from Prunus mume flowers. J. Beijing For. Univ. 32:201-206.

Zhong, H., J. Chen, C. Li, L. Chen, J. Wu, J. Chen, W. Lu, and J. Li. 2011. Selection of reliable reference genes for expression studies by reverse transcription quantitative real-time PCR in litchi under different experimental conditions. Plant Cell Rpt. 30:641-653.

Zhu, J., L. Zhang, W. Li, S. Han, W. Yang, and L. Qi. 2013. Reference gene selection for quantitative real-time PCR normalization in Caragana intermedia under different abiotic stress conditions. PLoS One 8:e53196.

Zhu, X., X. Li, W. Chen, J. Chen, W. Lu, L. Chen, and D. Fu. 2012. Evaluation of new reference genes in papaya for accurate transcript normalization under different experimental conditions. PLoS One 7:e44405. 


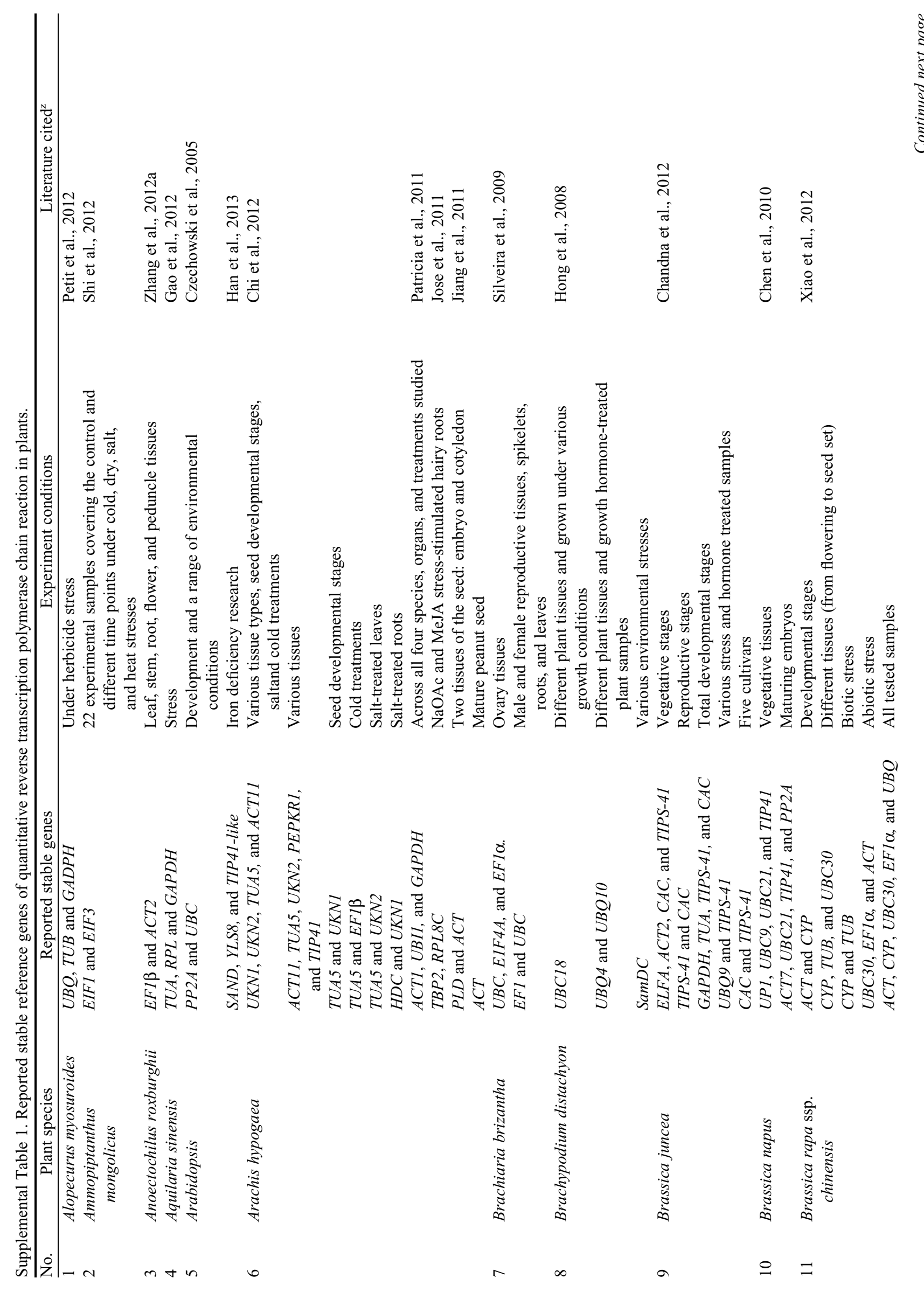




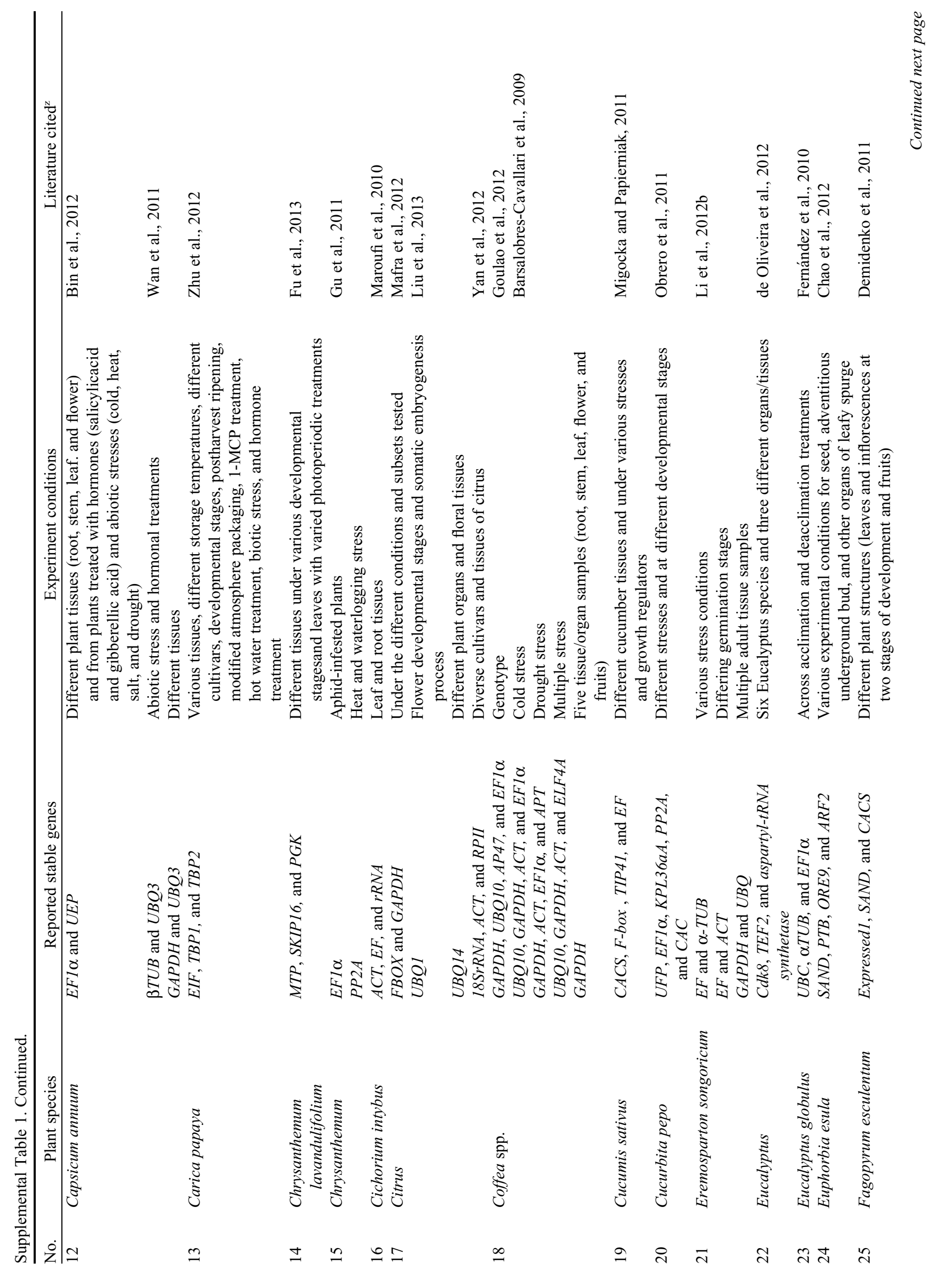




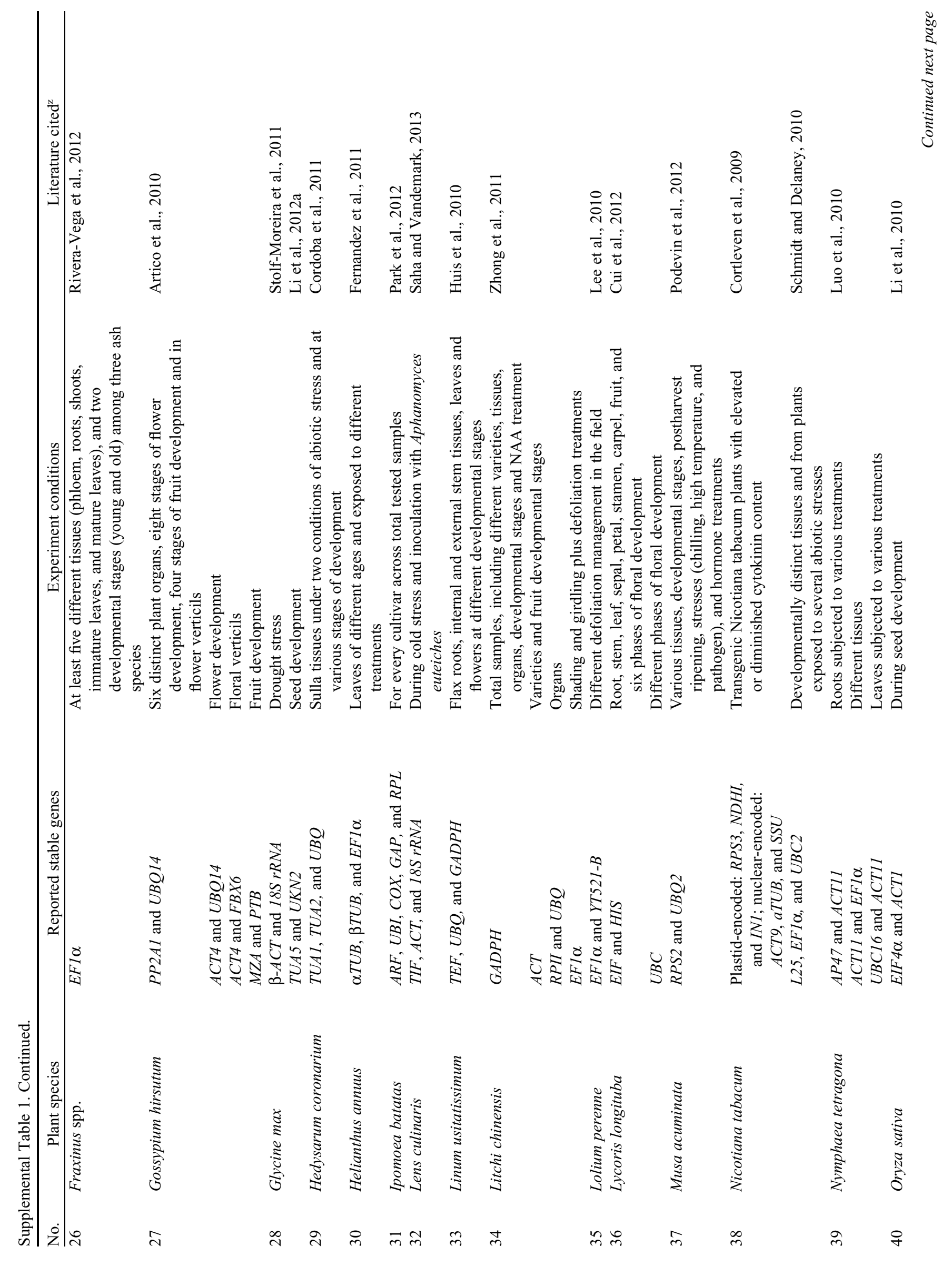


$\overline{\overrightarrow{5}}$

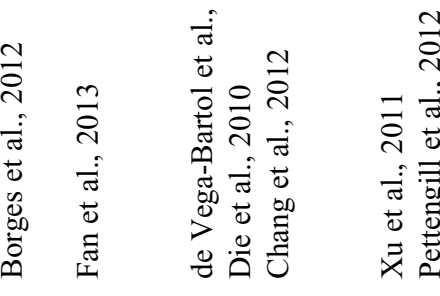

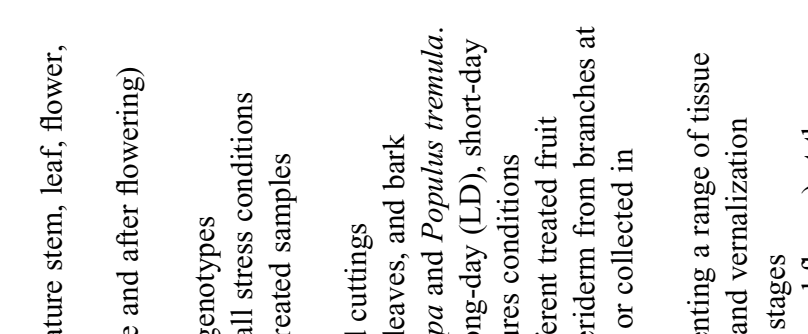

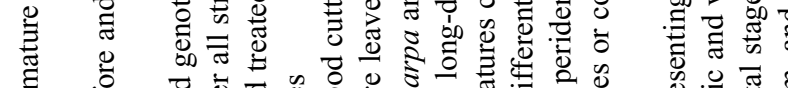

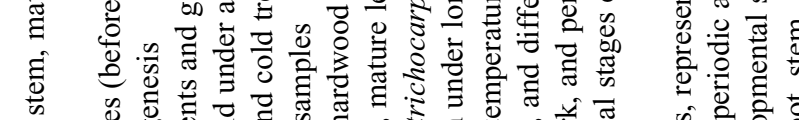

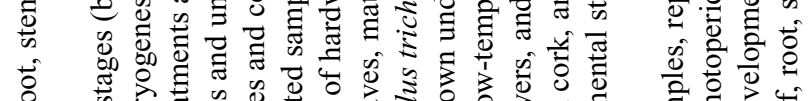

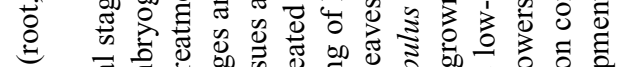

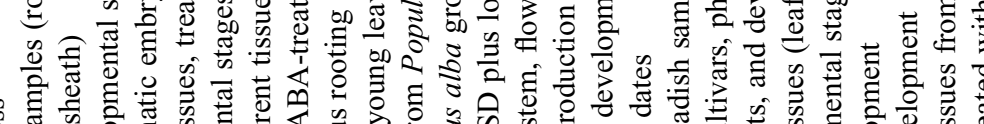

究

$\Xi$

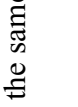

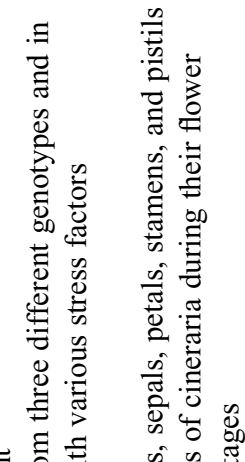

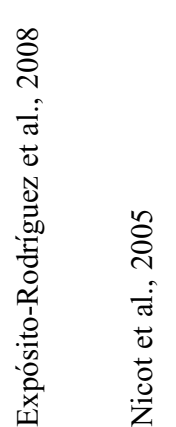

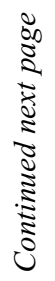

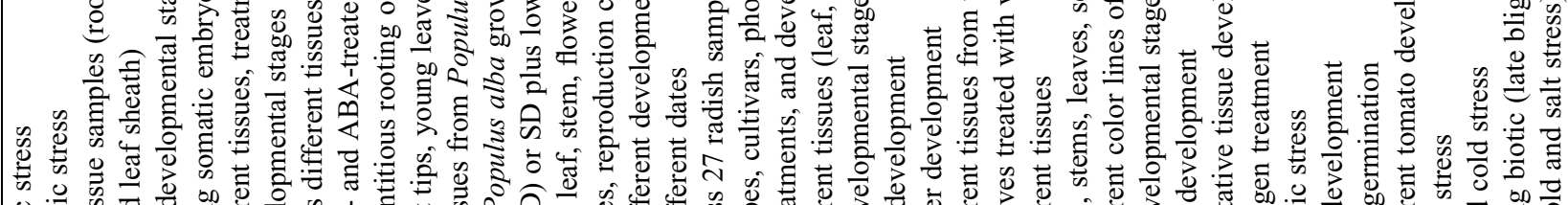

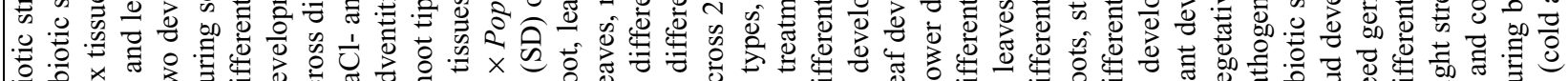

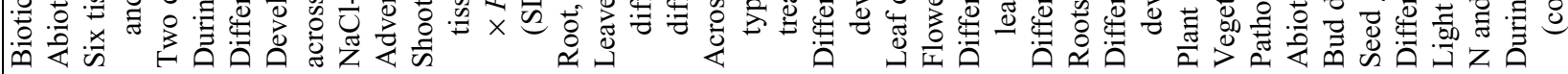

$\frac{2}{\pi}$

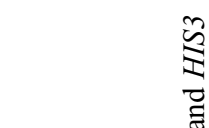

焉

()

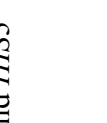

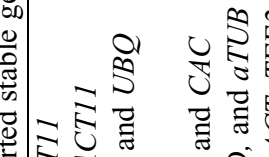

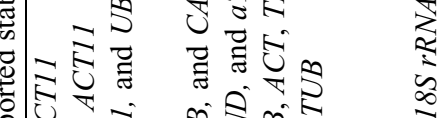

के

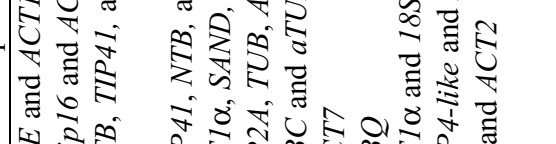

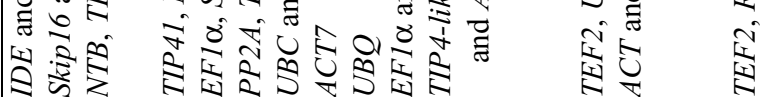

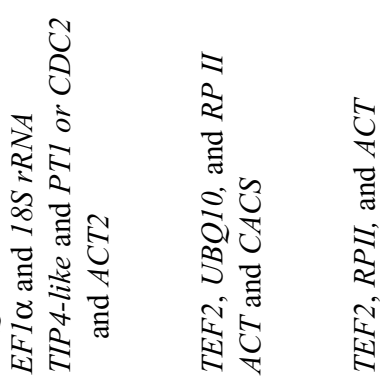

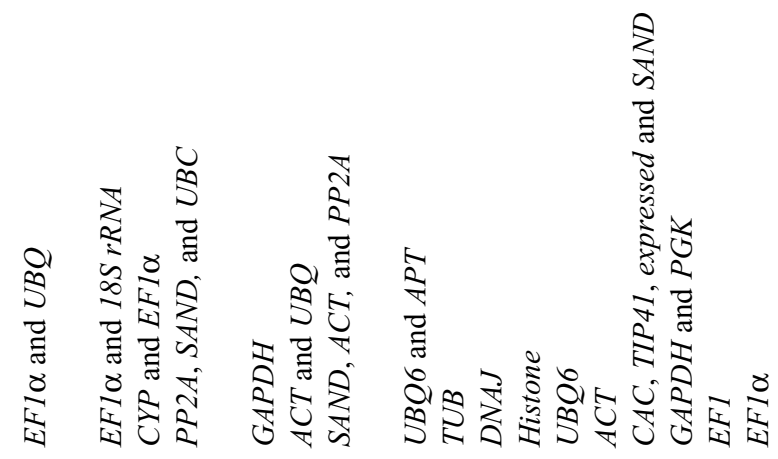

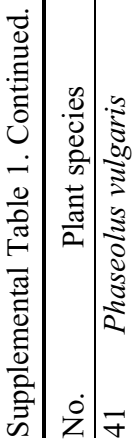

$\frac{2}{3}$

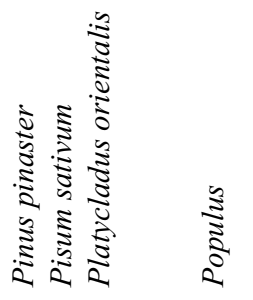

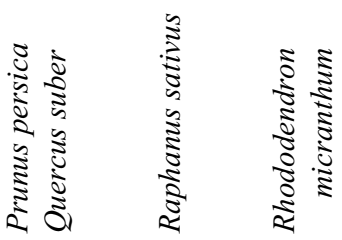

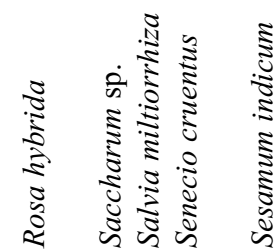

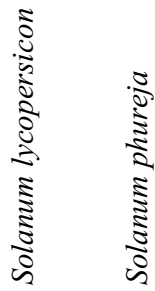

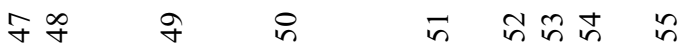

in $\quad$ in 


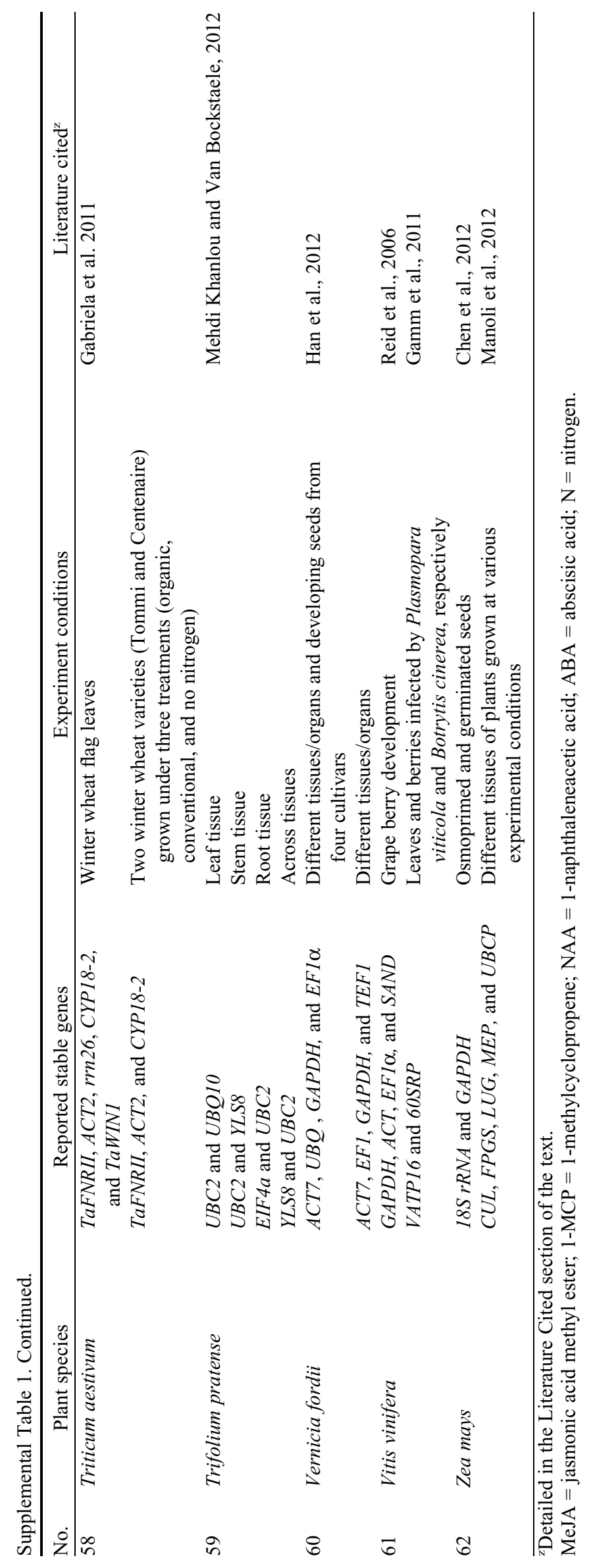


Supplemental Table 2A. Expression stability of the reference genes calculated by NormFinder (Andersen et al., 2004). ${ }^{z}$

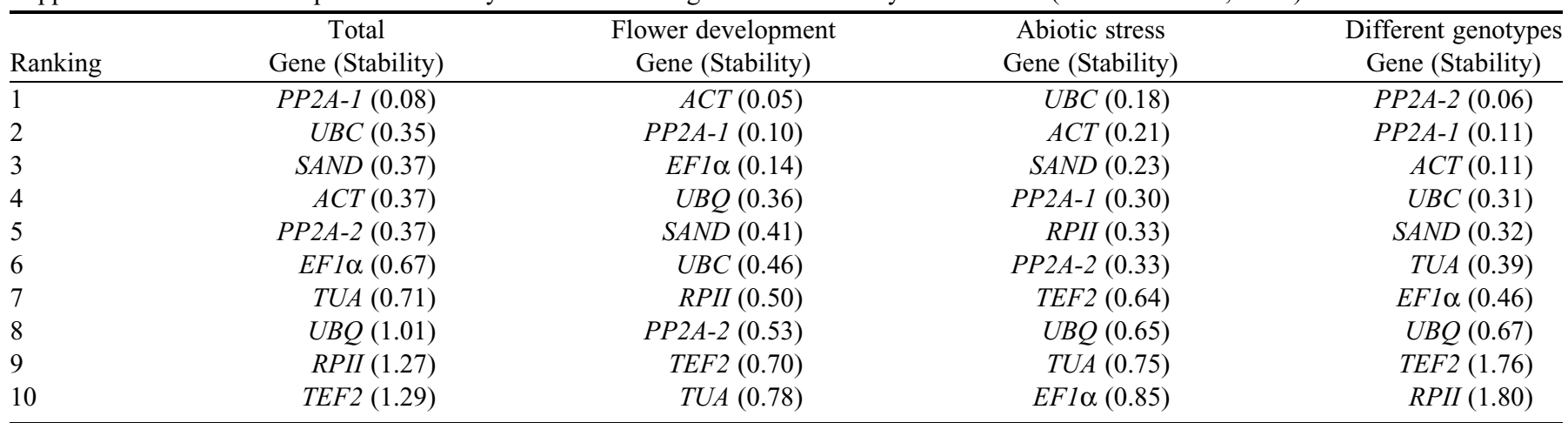

${ }^{\mathrm{z}}$ Reference genes with the lowest stability values were identified as the most stable genes by NormFinder (Andersen et al., 2004).

Supplemental Table 2B. Expression stability of the reference genes calculated by BestKeeper (Pfaffl et al., 2004). ${ }^{\mathrm{z}}$

\begin{tabular}{|c|c|c|c|c|}
\hline Ranking & $\begin{array}{c}\text { Total } \\
\text { Gene }\left(\mathrm{CV}^{\mathrm{y}} \pm \mathrm{SD}^{\mathrm{x}}\right)\end{array}$ & $\begin{array}{c}\text { Flower development } \\
\text { Gene }\left(\mathrm{CV}^{\mathrm{y}} \pm \mathrm{SD}^{\mathrm{x}}\right)\end{array}$ & $\begin{array}{c}\text { Abiotic stress } \\
\text { Gene }\left(\mathrm{CV}^{\mathrm{y}} \pm \mathrm{SD}^{\mathrm{x}}\right)\end{array}$ & $\begin{array}{c}\text { Different genotypes } \\
\text { Gene }\left(\mathrm{CV}^{\mathrm{y}} \pm \mathrm{SD}^{\mathrm{x}}\right)\end{array}$ \\
\hline 1 & $P P 2 A-1(3.42 \pm 0.76)$ & $P P 2 A-2(3.60 \pm 0.78)$ & $U B C(0.76 \pm 0.15)$ & $U B C(1.17 \pm 0.22)$ \\
\hline 2 & RPII $(3.49 \pm 0.82)$ & $P P 2 A-1(4.18 \pm 0.93)$ & $\operatorname{SAND}(0.86 \pm 0.21)$ & $P P 2 A-2(1.45 \pm 0.30)$ \\
\hline 4 & $S A N D(3.86 \pm 0.95)$ & $R P I I(4.52 \pm 1.04)$ & $R P I I(1.77 \pm 0.41)$ & $S A N D(1.98 \pm 0.48)$ \\
\hline 5 & $U B C(3.98 \pm 0.76)$ & $S A N D(5.065 \pm 1.27)$ & $P P 2 A-2(1.94 \pm 0.40)$ & $A C T(2.34 \pm 0.41)$ \\
\hline 6 & $E F 1 \alpha(4.16 \pm 0.82)$ & $E F 1 \alpha(5.44 \pm 1.07)$ & $P P 2 A-1(2.07 \pm 0.47)$ & $E F 1 \alpha(3.03 \pm 0.61)$ \\
\hline 8 & $A C T(5.77 \pm 1.08)$ & $U B Q(6.05 \pm 1.28)$ & $T U A(2.99 \pm 0.62)$ & $U B Q(3.566 \pm 0.82)$ \\
\hline 9 & $U B Q(5.94 \pm 1.33)$ & TEF2 $(7.63 \pm 1.81)$ & $U B Q(3.84 \pm 0.86)$ & TEF2 $(6.83 \pm 1.53)$ \\
\hline 10 & $T U A(6.02 \pm 1.23)$ & $T U A(8.50 \pm 1.82)$ & $\operatorname{EF} 1 \alpha(5.26 \pm 1.03)$ & $R P I I(10.19 \pm 2.22)$ \\
\hline
\end{tabular}

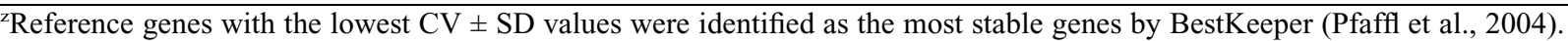

${ }^{\mathrm{y}} \mathrm{V}=$ Coefficient of variation of the raw $\mathrm{Cq}$ values.

${ }^{\mathrm{x}} \mathrm{SD}=$ The standard deviation of the raw Cq values.

Supplemental Table 2C. Pairwise variation (V)

\begin{tabular}{lllllllll}
\hline & $\mathrm{V} 2 / 3$ & $\mathrm{~V} 3 / 4$ & $\mathrm{~V} 4 / 5$ & $\mathrm{~V} 5 / 6$ & $\mathrm{~V} 6 / 7$ & $\mathrm{~V} 7 / 8$ & $\mathrm{~V} 8 / 9$ & $\mathrm{~V} 9 / 10$ \\
\hline Total & 0.189 & 0.149 & 0.14 & 0.157 & 0.159 & 0.182 & 0.202 & 0.189 \\
Flower development & 0.19 & 0.11 & 0.112 & 0.112 & 0.092 & 0.09 & 0.122 & 0.114 \\
Abiotic stress & 0.127 & 0.121 & 0.134 & 0.095 & 0.126 & 0.11 & 0.122 & 0.125 \\
Different genotypes & 0.122 & 0.079 & 0.1 & 0.095 & 0.108 & 0.126 & 0.278 & 0.262 \\
\hline
\end{tabular}
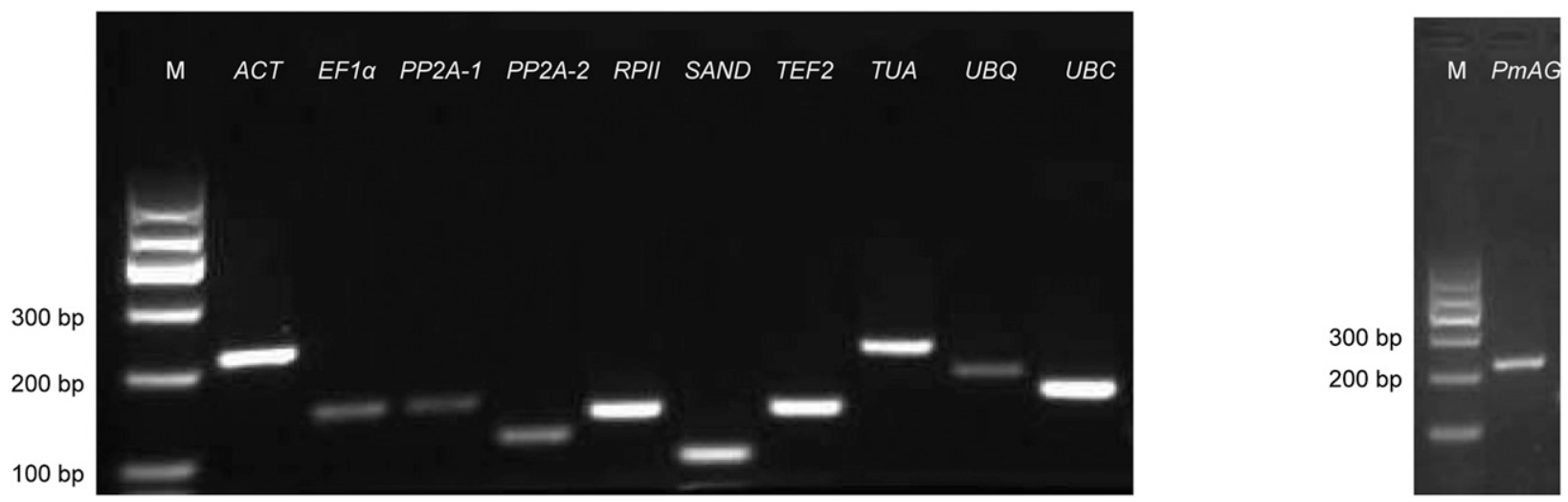

Supplemental Fig. 1. Polymerase chain reaction amplification specificity of the 10 reference genes and $P m A G$ gene. Only a single amplification product for each primer pair with the expected amplicon size was verified by $2 \%$ agarose gel electrophoresis. $\mathrm{M}=$ Marker D2000; $A C T=$ actin gene; $E F 1 \alpha=$ elongation factor 1 -alpha gene; $P P 2 A=$ protein phosphatase $2 \mathrm{~A}$ gene; $R P I I=$ RNA polymerase II gene; $S A N D=$ SAND family protein gene; $T E F 2=$ translation elongation factor 2 gene; $T U A=$ alpha tubulin gene; $U B Q=$ ubiquitin gene; $U B C=$ ubiquitin-conjugating enzyme E2 gene; PmAG = an AGAMOUS homolog gene of $A$. thaliana. 

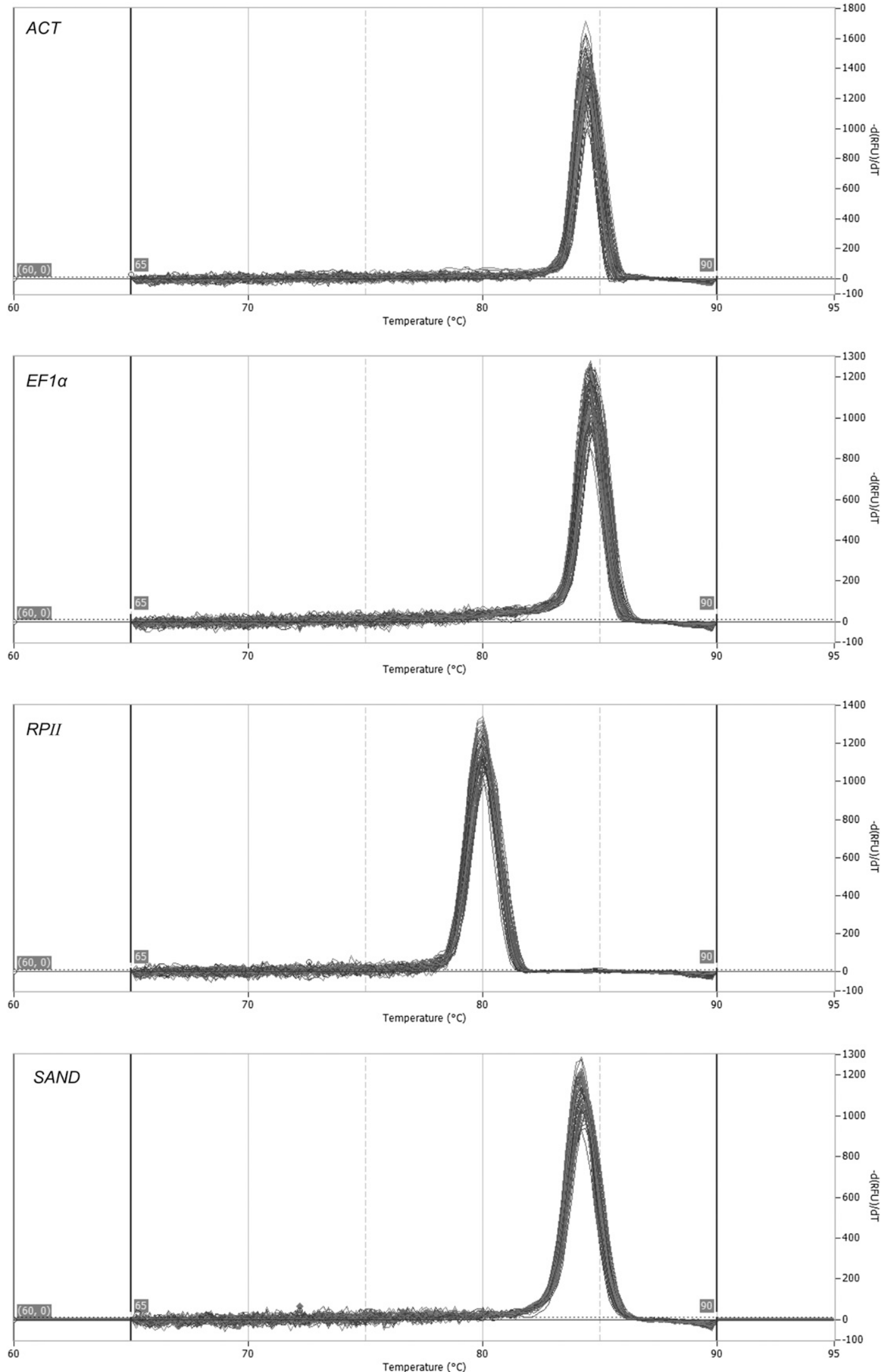

Supplemental Fig. 2. Melting curves of the 10 reference genes and $P m A G$ gene. $A C T=$ actin gene; $E F 1 \alpha=$ elongation factor 1 -alpha gene; $P P 2 A=$ protein phosphatase $2 \mathrm{~A}$ gene; $R P I I=$ RNA polymerase II gene; $S A N D=$ SAND family protein gene; $T E F 2=$ translation elongation factor 2 gene; $T U A=$ alpha tubulin gene; $U B Q=$ ubiquitin gene; $U B C=$ ubiquitin-conjugating enzyme E2 gene; $P m A G=$ an AGAMOUS homolog gene of $A$. thaliana; Temperature $\left({ }^{\circ} \mathrm{C}\right)=$ the amplification temperature; $-\mathrm{d}(\mathrm{RFU}) / \mathrm{dT}=$ the rate of change of the relative fluorescence units (RFU) with time $(\mathrm{T})$. 

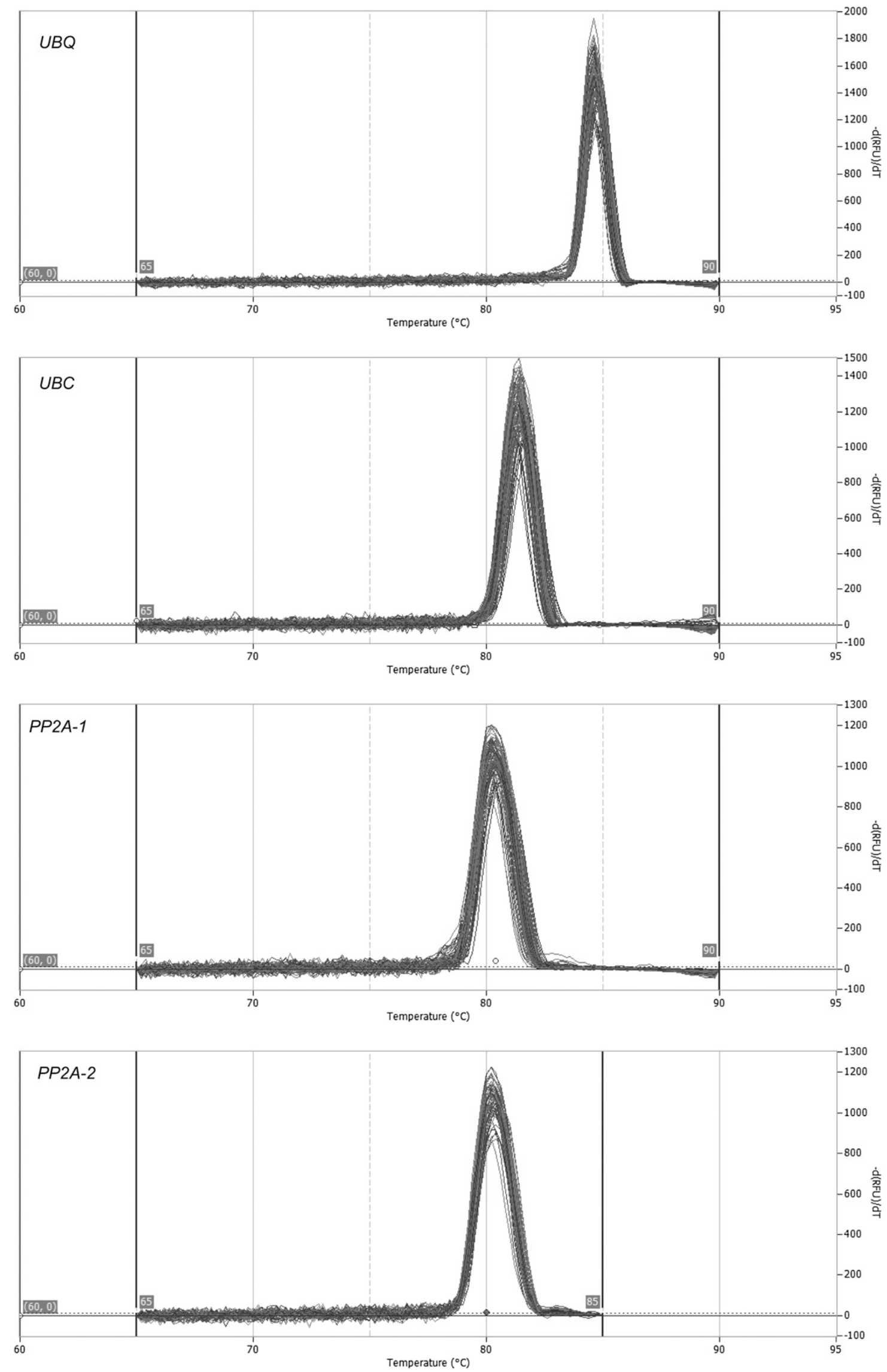

Supplemental Fig. 2. Continued. 

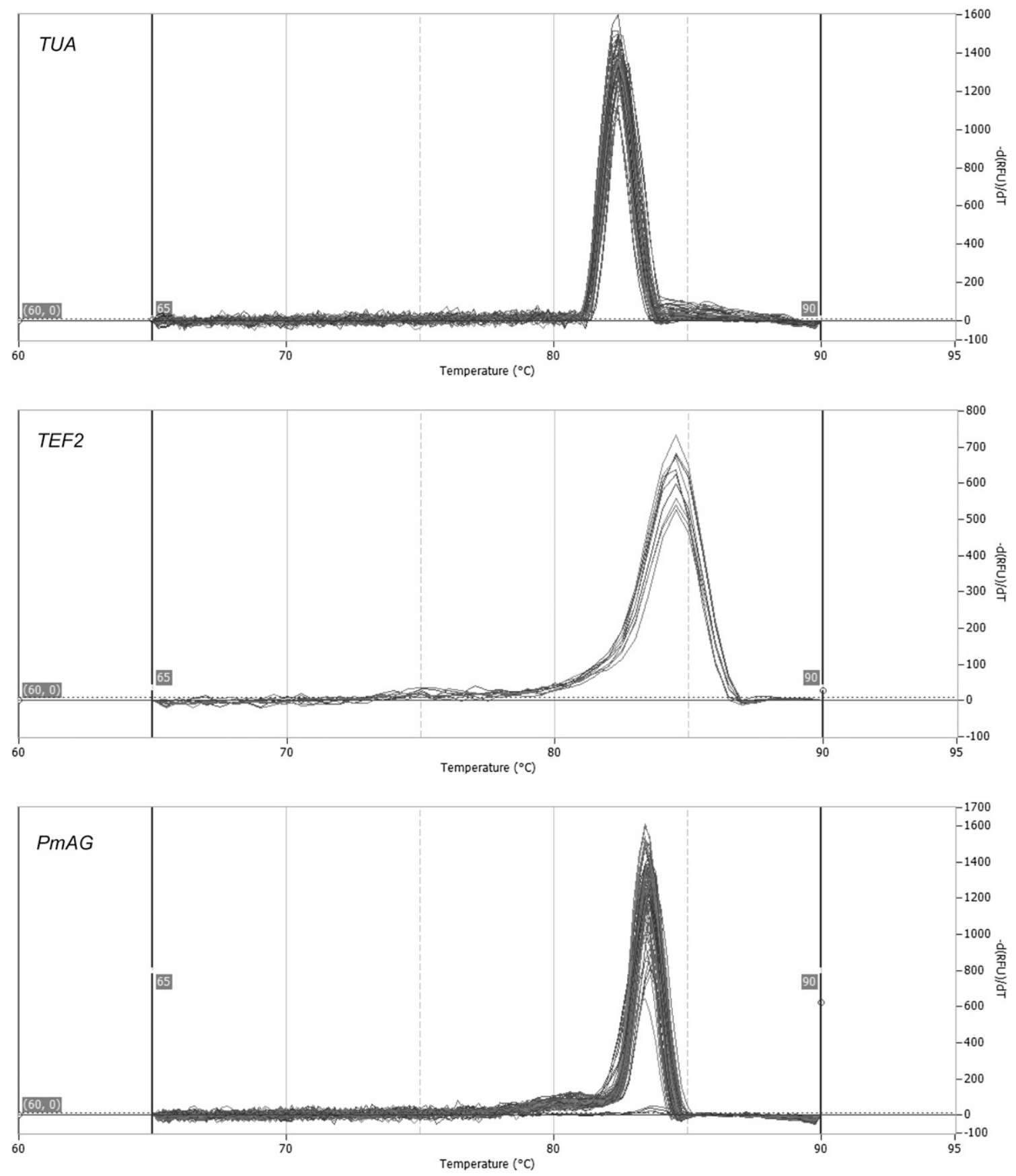

Supplemental Fig. 2. Continued. 